\title{
Deployment of the consultation-liaison model in adult and child-adolescent psychiatry and its impact on improving mental health treatment
}

\author{
M.-J. Fleury ${ }^{1,2^{*}}$, G. Grenier ${ }^{2}$, L. Gentil ${ }^{2}$ and P. Roberge ${ }^{3}$
}

\begin{abstract}
Background: Little information exists on the perceptions of psychiatrists regarding the implementation and various impacts of the consultation-liaison model. This model has been used in Quebec (Canada) through the function of specialist respondent-psychiatrists (SRP) since 2009. This study assessed the main activities, barriers or facilitators, and impact of SRP in adult and child-adolescent psychiatry on the capacity of service providers in primary care and youth centers to treat patients with mental health disorders (MHD).
\end{abstract}

Methods: Data included 126 self-administered questionnaires from SRP and semi-structured interviews from 48 SRP managers. Mixed methods were used, with qualitative findings from managers complementing the SRP survey. Comparative analyses of SRP responses in adult versus child-adolescent psychiatry were also conducted.

Results: Psychiatrists dedicated a median $24.12 \mathrm{~h}$ /month to the SRP function, mainly involving case discussions with primary care teams or youth centers. They were confident about the level of support they provided and satisfied with their influence in clinical decision-making, but less satisfied with the support provided by their organizations. SRP evaluated their impacts on clinical practice as moderate, particularly among general practitioners (GP). SRP working in child-adolescent psychiatry were more comfortable, motivated, and positive about their overall performance and impact than in adult psychiatry. Organizational barriers (e.g. team instability) were most prevalent, followed by system-level factors (e.g. network size and complexity, lack of resources, model inflexibility) and individual factors (e.g. GP reluctance to treat patients with MHD). Organizational facilitators included support from family medicine group directors, collaboration with university family medicine groups and coordination by liaison nurses; at the system level, pre-existing relationships and working in the same institution; while individual-level facilitators included SRP personality and strong organizational support.

Conclusion: Quebec SRP were implemented sparingly in family medicine groups and youth centers, while SRP viewed their overall impact as moderate. Results were more positive in child-adolescent psychiatry than in adult psychiatry. Increased support for the SRP function, adapting the model to GP in need of more direct support, and resolving key system issues may improve SRP effectiveness in terms of team stability, coordination among providers, access to $\mathrm{MH}$ services and readiness to implement innovations.

\footnotetext{
*Correspondence: flemar@douglas.mcgill.ca

1 Department of Psychiatry, McGill University, Montreal, QC, Canada

Full list of author information is available at the end of the article
} original author(s) and the source, provide a link to the Creative Commons licence, and indicate if changes were made. The images or other third party material in this article are included in the article's Creative Commons licence, unless indicated otherwise in a credit line to the material. If material is not included in the article's Creative Commons licence and your intended use is not permitted by statutory regulation or exceeds the permitted use, you will need to obtain permission directly from the copyright holder. To view a copy of this licence, visit http://creativecommons.org/licenses/by/4.0/. The Creative Commons Public Domain Dedication waiver (http://creativeco mmons.org/publicdomain/zero/1.0/) applies to the data made available in this article, unless otherwise stated in a credit line to the data. 
Keywords: Consultation-liaison model, Specialist respondent psychiatrists, Adult psychiatry, Child psychiatry, Adolescent psychiatry, Primary care, Barriers or facilitators, Model impacts

\section{Background}

Most individuals affected by mental health disorders (MHD) use primary care services as the point of entry to the mental health $(\mathrm{MH})$ care system. Primary care is the gatekeepers to specialized MH services in Quebec (Canada), as in many countries $[1,2]$. General practitioners (GP) are the main primary care providers, evaluating and treating in their clinics from 20 to $40 \%$ of patients with MHD annually [3-6]. Primary care services are less costly and stigmatizing, and more accessible than specialized MH services [7, 8]. Yet studies have reported limited capacity among primary care clinicians, especially GP, to diagnose and treat $\mathrm{MH}$ conditions, particularly severe or co-occurring MHD [5, 9-12] and substance-related disorders [13]. Better integration of specialized MH services into primary care has thus been strongly recommended and is at the heart of current international $[14,15]$ and Canadian [16] MH reforms.

Several models for integrating $\mathrm{MH}$ and primary care services have been developed in the past decades, including collaborative care [17], shared care [9] and the consultation-liaison model [18]. Collaborative and shared care originated with the Wagner chronic care model [19]. In shared care, psychiatrists work closely with GP [20], whereas collaborative care involves nurses, psychologists, social workers and other clinicians [21, 22], integrating three core work components: use of systematic psychiatric assessments; longitudinal patient monitoring and care management usually performed by nurses; and stepped-care recommendations by psychiatrists or other $\mathrm{MH}$ specialists [23]. Both collaborative and shared care may target specific populations (e.g. elderly, children and adolescents) and include clinician collaboration of varying intensity [22]. In the consultation-liaison model, psychiatrists hold regular case discussions with GP or other primary care clinicians, providing care management, clinician support and referrals without seeing patients directly [24-26]. The psychiatrist function is focused essentially on improving clinician skills [27]. Compared with the collaborative and shared care models, the consultation-liaison model implies fewer changes for primary care clinicians, as consultation-liaison essentially targets improvements to $\mathrm{MH}$ expertise, without reorganizing other areas of interdisciplinary group practice. Hybrid models also exist that blend characteristics of the three generic models $[28,29]$.

Randomized controlled trials have assessed the impacts of $\mathrm{MH}$ service integration in primary care on patient health outcomes [29-40] and determined that these models reduced psychiatric symptoms among patients with depression [29, 38, 39, 41-43], anxiety disorders [29, 40, 44], bipolar disorders [45] and multiple MHD [31]. Other studies focused on health service use found that integrated $\mathrm{MH}$ services increased access to $\mathrm{MH}$ services $[20,21]$ and reduced psychiatric hospitalizations [46, 47]. Other studies evaluated the impacts of $\mathrm{MH}$ service integration in primary care on clinical practice revealed improved MH screening [48-50] and prescribing practices [48].

Concerning the consultation-liaison model, patient outcome research found that the model improved $\mathrm{MH}$ conditions in the first 3 months of treatment while improvements in co-occurring MHD, alcohol and cannabis use appeared after 4 months [35]; depressive symptoms diminished as effectively with the consultation-liaison model as with collaborative care at 9-month follow-up [32]. Concerning heath service use, the consultation-liaison model improved treatment adherence and satisfaction with services between 3 and 12 months posttreatment [30], promoting efficiency in specialized $\mathrm{MH}$ service use $[18,27]$. Finally, clinical practice improved in terms of GP knowledge and skills in diagnosing and treating patients with MHD [30,51], medication prescribing [51], inter-professional communication $[51,52]$ and less stigmatizing attitudes [53].

Qualitative studies have assessed barriers and facilitators in implementing integrated $\mathrm{MH}$ services into primary care around multiple issues. At the systemlevel these included supportive legislative/policy environment $[25,54]$, availability of appropriate resources [55], preexisting relationships between specialized $\mathrm{MH}$ services and primary care $[22,56]$, and adequate incentives [25, 57-59]. Organizational-level issues included clinician acceptance of the model $[60,61]$, team stability [55], organizational support [1, 62, 63], leadership [55, 62], and feedback on model effectiveness [59]. Finally, individual-level concerns included interest among GP in MHD [1, 25, 59, 63], and individual qualities of psychiatrists $[58,60]$.

As implementation of the consultation-liaison model was not expected to involve sweeping changes, this model was selected in Quebec with the aim of improving $\mathrm{MH}$ expertise among providers in primary care, and youth centers which are specialized services treating patients under 18 years old, a majority of whom with MHD [64]. Moreover, this MH reform only aimed 
at changing practices in the public $\mathrm{MH}$ sector, which excludes the majority of GP who work in private practices under the direction of another Quebec ministry. The Quebec consultation-liaison model was based on the deployment of a specialist respondent-psychiatrist (SRP) function, launched as part of the 2005 Quebec MH Action Plan to help consolidate MH expertise outside of specialized psychiatric care [65]. Yet even the introduction of this "simplified" model of integrated specialized $\mathrm{MH}$ care was strongly contested by the Quebec Association of Psychiatric Physicians. An agreement was finally signed in 2009 between the Association and the Quebec government, establishing a high hourly fee for psychiatrists willing to serve as SRP in their health networks as a strong incentive for them to integrate this function into their professional activities. Under the 2009 agreement [66], one or two SRP were allocated either per 50,000 inhabitant in adult psychiatry or per 50,000 patients under age 18 in child-adolescent psychiatry. SRP had to be present on-site for $3.5 \mathrm{~h} /$ weekly to train clinicians working in $\mathrm{MH}$ primary care teams (MH-PCT), onestop MH service teams, family medicine groups or youth centers, and provide on-call telephone availability during office hours between on-site visits.

MH-PCT and one-stop MH services were also mandated under the $2005 \mathrm{MH}$ Action Plan [65]. MH-PCT located in local community health centers, the main public primary care organizations in Quebec, were projected to include 20 interdisciplinary psychosocial professionals and two GP. However, these original objectives have yet to be completed $[67,68]$. One MH-PCT was allocated per 100,000 inhabitants among the health networks. MH-PCT offered individual and group therapies for patients with MHD. For networks with a minimum of 50,000 inhabitants, one-stop MH service teams were also established in local community health service centers as the point of entry for accessing $\mathrm{MH}$ services from either MH-PCT or psychiatric care. The one-stop MH service teams provide assessments for self-referred patients or those referred by GP, community organizations (voluntary sector) or by inter-sectorial resources (e.g. addiction rehabilitation centers). At the time they were created, one-stop $\mathrm{MH}$ service teams and MH-PCT were mainly staffed by $\mathrm{MH}$ professionals transferred from specialized $\mathrm{MH}$ services to primary care $[67,68]$. Established in 2002 [69], family medicine groups brought together GP working in private practices and integrated secretarial support, as well as multidisciplinary teams that mainly included nurses and in some cases other psychosocial clinicians like social workers. Financed by the government, the enhanced family medicine groups ensured patient registration, and better continuity of care and access to care as they offered more days and hours of medical coverage including work-in clinics [70]. By 2015 , more than $60 \%$ of GP in Quebec worked in family medicine groups [69]. Created in the 1970s [71], youth centers remain key partners in child-adolescent psychiatry offering specialized regional public services for children and adolescents in difficulty as well as psychosocial, rehabilitation, social integration and placement services [72]. In the consultation-liaison model, the SRP function included close working relationship with these four types of health care providers to reinforce their $\mathrm{MH}$ expertise with the aim of improving MHD treatment and increasing numbers of patients with MHD that these clinicians can overall treat.

While research has assessed impacts of the consultation-liaison and other integrated models on patients and GP or other psychosocial clinicians, few studies have explored the perspectives of psychiatrists working as SRP or their managers [25, 58, 73, 74]. Moreover, impacts of the consultation-liaison model and related barriers/facilitators have rarely been considered [25, 58], nor to our knowledge have studies compared implementation of the consultation-liaison model in adult versus child-adolescent psychiatry. A better understanding of SRP perspectives on the consultation-liaison model may help improve future implementation and adaptation of the model leading to better outcomes, while providing guidance to decision-makers involved with future $\mathrm{MH}$ reforms, whether in Quebec or elsewhere, especially considering that primary care $\mathrm{MH}$ consolidation is a key issue for service improvement. This study may also identify previously unknown barriers or facilitators regarding the implementation of integrated models such as consultation-liaison. Accordingly, this study assessed the main activities of SRP and barriers or facilitators affecting the SRP function from the perspectives of SRP and managers and compared the impacts of SRP in adult and child-adolescent psychiatry in terms of the capacity of Quebec GP, $\mathrm{MH}-\mathrm{PCT}$, one-stop $\mathrm{MH}$ service teams and youth centers to care for patients with MHD.

\section{Methods \\ Study context}

In Canada, health and social services are under provincial jurisdiction and are covered by a universal health insurance system [75]. The Canadian and Quebec health and MH systems have been criticized over the years for inadequate access and continuity of care $[76,77]$ and for less than optimal consolidation of services within primary care $[76,78]$. In the province of Quebec, which accounts for 23\% of the Canadian population [79], some $25 \%$ of inhabitants are without a "family doctor", and instead use walk-in clinics as a regular source of care $[80,81]$. Wait times to access 
$\mathrm{MH}-\mathrm{PCT}$ and psychiatric care are also quite long, varying from several months to more than a year especially for psychiatric care in some Quebec territories $[67,82]$. Benchmarks originally set for access to treatment were 1-month for MH-PCT and evaluations within 7-days were promoted for the one-stop $\mathrm{MH}$ service teams [65], yet these standards have to be met due to organizational issues and high patient demand $[67,68,83]$.

In this context, major recent reforms have been ordered aimed at decreasing the overall number of Quebec health providers while integrating network services; a more recent focus is on the implementation of clinical best practices. In particular, the 2015 health reform [84] created 22 integrated health and social service centers in Quebec, nine of them university-affiliated, merging all public health and social service organizations like hospitals, local community health service centers (including MH-PCT and one-stop MH services) and youth centers into 22 networks (except for 12 university hospitals). Each $\mathrm{MH}$ network includes specialized services offered in psychiatric departments of general hospitals or psychiatric hospitals staffed by approximately 1,200 psychiatrists, most ( $\pm 90 \%)$ working in hospitals [85] and about $44 \%$ located in metropolitan Montreal or Quebec, the capital city [86]. Of a total 37 psychiatric departments, 23 serve both adults and children or adolescents through multidisciplinary teams consisting mainly of nurses, psychologists, occupational therapists and social workers. These public MH networks also work in conjunction with GP employed in private family medicine groups on fee-for-service payment schemes to further consolidate $\mathrm{MH}$ expertise and better serve patients with MHD.

\section{Study design}

The study used a sequential explanatory mixed-method design $[87,88]$, with qualitative findings from psychiatric department heads (hereafter: "managers") on deployment of the consultation-liaison model used to explain and complement the quantitative data from a survey of SRP on their activities and impacts. Mixed methods are particularly useful for understanding the implementation of new programs or reforms [87]. The study was also designed in collaboration with an advisory committee, consisting of representatives from the Quebec Health and Social Services Ministry, the Quebec Association of Psychiatric Physicians, chiefs of psychiatry at MH university institutes and SRP leaders.

\section{Data collection and instruments}

SRP survey data were collected using a self-administered questionnaire and quantitative information from managers using semi-structured interviews. Data collection took place from June 2019 to February 2020 (see
Supplementary materials). The questionnaire and interview guide were validated by the advisory committee, and pre-tested by three SRP and three managers. Interviews were conducted by a senior research agent trained and closely monitored by the study researchers. Questionnaire responses were reviewed by the project coordinator to verify that all questions were fully addressed and ensure data quality. The SRP questionnaire required $30 \mathrm{~min}$ to complete, while interviews with managers lasted $60 \mathrm{~min}$ on average.

The SRP questionnaire included: (1) socio-demographic and professional data (e.g. age, years as SRP); (2) professional activities (e.g. hours per month dedicated to case discussions, telephone availability); (3) profiles of patients discussed or seen (e.g. diagnoses, service use); and (4) perceived impacts of SRP function (e.g. on $\mathrm{GP}$ or in $\mathrm{MH}$ teams). Manager interviews addressed the organization of SRP (e.g. work integration with MH-PCT or GP) and barriers or facilitators to SRP effectiveness. Manager socio-demographic and professional data (e.g. age, seniority) were also collected through a brief questionnaire ( $3 \mathrm{~min}$ ) administered prior to the interviews.

\section{Recruitment process}

First, all departmental managers were contacted to obtain a list of SRP in their respective territories and invited to participate in a semi-structured telephone interview. Invitations to complete the questionnaire were then sent to SRP by email, fax or through departmental secretaries. Up to 12 automatic reminders or emails were sent to non-responders after 2 weeks, or follow-up telephone calls made. Help with recruitment was also sought from the project advisory committee members (December 2019, January 2020). Managers were solicited as often as four times to maximize participation in the study. All participants provided informed consent. The research ethics board of the Douglas MH university institute approved the study protocol.

\section{Analysis}

Regarding quantitative data from SRP questionnaires, the very few missing data found $(<5 \%)$ were replaced by the means. First, descriptive statistics including percentages for categorical variables and median or mean values for continuous variables were produced. Second, comparative analyses were conducted to test differences in responses among SRP in adult and child-adolescent psychiatry using the Mann-Whitney U test and Anova. Quantitative data from managers were analyzed using content analysis based on a four-step process [89]: 1) audio-recording of interviews and verbatim transcription; 2) preliminary readings and selection of classification units based on $10 \%$ of the verbatim by two research 
team members working independently, and verification of their high inter-rater reliability by researchers; 3 ) separation of content of the entire verbatim into units of meaning framed by the interview guide and more broadly, by system, organizational and individual-level barriers or facilitators to deployment of the SRP function; and 4) quantification of qualitative data for weighing the importance of issues discussed by managers. The triangulation process involved: a) summarizing the quantitative data in tables, b) synthesizing the quantitative data in a document, c) validating agreement between results of the SRP survey with information provided by manager, $d$ ) and using data from the qualitative investigation to further describe the quantitative results.

\section{Results}

\section{Sample description (data from questionnaires)}

Of 214 SRP identified by managers, 126 participated (response rate $=59 \%$ ). SRP were mainly female $(69 \%)$ and 48 years old on average, had worked 16 years as a psychiatrist and six as SRP. Nearly all (90\%) were active SRP, $75 \%$ working in adult psychiatry, $25 \%$ in child-adolescent psychiatry, $65 \%$ in general hospital settings versus $35 \%$ in psychiatric hospitals, while $42 \%$ were in university health regions versus $24 \%, 19 \%$ and $15 \%$ in peripheral, remote and intermediary regions, respectively. Of 55 managers invited to the study, 48 participated (response rate $=87 \%)$. Managers were mainly female $(59 \%)$, mean 50 years old with an average of 18 years as a psychiatrist and eight as manager. Moreover, $90 \%$ previously or currently worked as SRP, $60 \%$ in adult psychiatry and $40 \%$ in child-adolescent psychiatry.

\section{SRP activities (data from the SRP questionnaire and manager interviews)}

Table 1 presents the main SRP activities based on the questionnaire. SRP devoted $24.12 \mathrm{~h} /$ month on average to their functions, mainly including case discussion meetings, followed by patient consultations with/without clinicians, telephone/video consultations and other. Most SRP (88-96\%) performed all these activities, except for patient consultations reported by $56 \%$. Specifically, they provided consultations to one-stop $\mathrm{MH}$ service teams (21\%), MH-PCT (20\%), GP (16\%) and youth center patients (10\%). Total hours/month reported by SRP and the number of telephone/video consultations with GP and one-stop $\mathrm{MH}$ service teams were significantly higher in adult versus child-adolescent psychiatry, whereas the number of SRP consultations with MH-PCT patients was significantly higher in child-adolescent psychiatry than in adult psychiatry.

Table 2 shows the distribution of specific clinical activities per month among SRP. Their time was mainly allocated to GP for pharmaceutical recommendations, to $\mathrm{MH}-\mathrm{PCT}$ and youth centers for psychosocial and psychotherapeutic recommendations, and to one stop $\mathrm{MH}$ service teams for referrals within health service networks. SRP in child-adolescent psychiatry devoted significantly more time toward information sharing on MHD in $\mathrm{MH}-$ PCT than those in adult psychiatry.

According to $40 \%$ of managers, the total hours covered by SRP was below their cap for 2009 , while $10 \%$ stated that SRP offered more time than required; the remaining $50 \%$ reported rates of SRP coverage in line with government regulations. Questionnaire results indicate that SRP reached 22.0 GP on average, 11.6 clinicians from MH-PCT, 6.2 from one stop MH service teams, and 3.8 from youth centers. SRP in adult psychiatry reached significantly more GP than those in child-adolescent psychiatry (mean 25.6 vs 11.3) and relatively fewer clinicians from adult vs. child-adolescent MH-PCT (9.4 vs 18.0). Managers identified that most network psychiatrists were registered as SRP and provided rotating telephone coverage for brief patient consultations with GP during office hours. However, GP used this service sparingly (median $3 \mathrm{~h} /$ month: Table 1 ).

Managers reported that SRP usually divided their work between sub-networks or MH-PCT and one stop MH service teams or GP family medicine groups. SRP worked with all or most network MH-PCT and one stop MH service teams, whereas half or fewer networks developed partnerships between SRP and GP. MH-PCT consultations were carefully prepared, with psychosocial clinicians sending patient case discussions to SRP in advance; GP were generally not involved in MH-PCT. A maximum of six cases difficult to manage in MH-PCT and requiring SRP assistance were usually discussed per session. SRP provided guidance and recommended treatment based on patient profiles. In one stop $\mathrm{MH}$ service teams, SRP mainly supported nurses in evaluating $\mathrm{MH}$ demands and orienting patients to appropriate services: whether a return to GP with clinical guidance, referral to the MH-PCT, community services or specialized care to the network hospital link evaluation modules ("module d'évaluation/liaison"). In some networks, SRP or liaisonnurses occasionally met patients for more extended evaluation or provided brief treatment during the wait period for transfer. GP were updated concerning patient profiles and treatments. Regarding family medicine groups in the networks, roughly half of managers noted that the SRP function had not been promoted; only $20 \%$ had presented this function to GP through memos, presentations at clinics or to clinic representatives. SRP services had higher priority in larger family medicine groups and those in closer proximity to hospitals employing SRP, in clinics with greater interest in $\mathrm{MH}$ and in those where 
Table 1 Specialist respondent-psychiatrist (SRP) activities per month

\begin{tabular}{|c|c|c|c|c|c|c|c|}
\hline & Total $(n=126)$ & $\operatorname{Median}^{\mathrm{a}}(\mathrm{IQR})^{\mathrm{b}}$ & $\begin{array}{l}\text { Adult } \\
\text { psychiatry } \\
(n=94)\end{array}$ & $\operatorname{Median}^{\mathrm{a}}(\mathrm{IQR})^{\mathrm{b}}$ & $\begin{array}{l}\text { Child-adolescent } \\
\text { psychiatry } \\
(n=32)\end{array}$ & $\operatorname{Median}^{\mathrm{a}}(\mathrm{IQR})^{\mathrm{b}}$ & Pvalue* \\
\hline \multicolumn{8}{|c|}{ a) Total hours for the following activities: } \\
\hline \multirow[t]{2}{*}{ Hours as SRP per month } & & $24.12(24.25)$ & & $28.20(25.75)$ & & $16.06(18.53)$ & 0.03 \\
\hline & $\mathrm{N}(\%)$ & & $\mathrm{N}(\%)$ & & $\mathrm{N}(\%)$ & & \\
\hline $\begin{array}{l}\text { Telephone/video consulta- } \\
\text { tions in hours per month } \\
\text { (total): number of SRP partici- } \\
\text { pating in the activity and time } \\
\text { spent per month }\end{array}$ & $111(88)$ & $5.00(13.26)$ & $85(90)$ & $8.00(17.00)$ & $26(81)$ & $5.45(9.25)$ & 0.02 \\
\hline $\begin{array}{l}\text { With general practition- } \\
\text { ers (GP) in family medicine } \\
\text { groups (subtotal) }\end{array}$ & $105(83)$ & $3.00(5.00)$ & $81(86)$ & $4.00(6.00)$ & $24(75)$ & $2.50(3.00)$ & 0.00 \\
\hline $\begin{array}{l}\text { With clinicians in mental } \\
\text { health }(\mathrm{MH}) \text { primary care } \\
\text { teams (MH-PCT) (subtotal) }\end{array}$ & $60(48)$ & $1.65(4.75)$ & $50(53)$ & $2.00(5.00)$ & $10(31)$ & $1.15(5.50)$ & 0.59 \\
\hline $\begin{array}{l}\text { With clinicians in one-stop } \\
\text { MH service teams (subtotal) }\end{array}$ & $72(57)$ & $2.00(5.00)$ & $57(61)$ & $2.27(5.00)$ & $15(47)$ & $1.50(1.00)$ & 0.02 \\
\hline $\begin{array}{l}\text { With clinicians in youth cent- } \\
\text { ers (subtotal) }\end{array}$ & $14(11)$ & $3.00(3.25)$ & 0 & 0 & $14(44)$ & $3.00(3.25)$ & \\
\hline $\begin{array}{l}\text { Case discussion meetings } \\
\text { (total): number of SRP partici- } \\
\text { pating in the activity and time } \\
\text { spent per month }\end{array}$ & $121(96)$ & $8.00(9.00)$ & $91(97)$ & $8.00(7.00)$ & $30(94)$ & $5.00(9.52)$ & 0.06 \\
\hline $\begin{array}{l}\text { With GP in family medicine } \\
\text { groups (subtotal) }\end{array}$ & $64(51)$ & $3.00(2.75)$ & $55(59)$ & $3.00(3.00)$ & $9(28)$ & $4.00(1.00)$ & 0.96 \\
\hline $\begin{array}{l}\text { With clinicians in MH-PCT } \\
\text { (subtotal) }\end{array}$ & $86(68)$ & $3.00(5.00)$ & $63(67)$ & $3.00(5.00)$ & $23(72)$ & $4.00(1.00)$ & 0.99 \\
\hline $\begin{array}{l}\text { With clinicians in one-stop } \\
\text { MH service teams (subtotal) }\end{array}$ & $75(60)$ & $4.00(5.00)$ & $62(66)$ & $4.00(5.00)$ & $13(41)$ & $4.00(4.50)$ & 0.67 \\
\hline $\begin{array}{l}\text { With clinicians in youth cent- } \\
\text { ers (subtotal) }\end{array}$ & $14(11)$ & $2.50(2.25)$ & 0 & 0 & $14(44)$ & $2.50(2.25)$ & \\
\hline $\begin{array}{l}\text { Consultations with patients } \\
\text { (including/not including } \\
\text { clinicians) (total): number of } \\
\text { SRP participating in the activ- } \\
\text { ity and time spent per month }\end{array}$ & $71(56)$ & $6.03(13.00)$ & $55(59)$ & $6.01(12.75)$ & $16(50)$ & $6.03(15.00)$ & 0.81 \\
\hline $\begin{array}{l}\text { With GP in family medicine } \\
\text { groups (subtotal) }\end{array}$ & $20(16)$ & $3.50(6.00)$ & $17(18)$ & $2.00(8.00)$ & $3(9)$ & $4.00(0.00)$ & 0.68 \\
\hline $\begin{array}{l}\text { With clinicians in MH-PCT } \\
\text { (subtotal) }\end{array}$ & $25(20)$ & $4.00(6.00)$ & $20(21)$ & $3.00(3.00)$ & $5(16)$ & $5.00(14.00)$ & 0.04 \\
\hline $\begin{array}{l}\text { With clinicians in one-stop } \\
\text { MH service teams (subtotal) }\end{array}$ & $26(21)$ & $3.00(3.33)$ & $21(22)$ & $3.00(3.00)$ & $5(16)$ & $0.71(2.29)$ & 0.08 \\
\hline $\begin{array}{l}\text { With clinicians in youth cent- } \\
\text { ers (subtotal) }\end{array}$ & $12(10)$ & 2.50 (3.79) & $1(1)$ & $1.00(0)$ & $11(34)$ & 3.00 (4.29) & 0.60 \\
\hline $\begin{array}{l}\text { Other activities (e.g. prepara- } \\
\text { tion or coordination of clinical } \\
\text { services, training, travel): } \\
\text { number of SRP participating } \\
\text { in the activity and time spent } \\
\text { per month }\end{array}$ & 117 (93) & $5.00(7.00)$ & $89(95)$ & $6.00(6.00)$ & $28(88)$ & $4.50(5.50)$ & 0.29 \\
\hline
\end{tabular}

${ }^{a}$ Median was chosen rather than mean due to the large variation in standard deviation

b IQR Interquartile range

${ }^{*}$ Mann-Whitney $\mathrm{U}$ test $p$ value 
Table 2 Distribution of follow-up clinical activities by specialist respondent-psychiatrists (SRP)

\begin{tabular}{|c|c|c|c|c|}
\hline $\begin{array}{l}\text { In percentage per month - distribution of follow-up clinical activities by SRP } \\
\text { (100\%): }\end{array}$ & $\begin{array}{l}\text { Total }(n=126) \\
\text { Mean (SD) }\end{array}$ & $\begin{array}{l}\text { Adult } \\
\text { psychiatry } \\
(n=94) \\
\text { Mean (SD) }\end{array}$ & $\begin{array}{l}\text { Child-adolescent } \\
\text { psychiatry }(n=32) \\
\text { Mean (SD) }\end{array}$ & Pvalue* \\
\hline $\begin{array}{l}\text { With general practitioners (GP) in family medicine groups with whom SRP } \\
\text { worked (N (\%)): }\end{array}$ & $106(84)^{\mathrm{a}}$ & $81(86)^{a}$ & $25(78)^{a}$ & \\
\hline Information on mental health disorders (MHD) & $17(11)$ & $18(11)$ & $13(10)$ & 0.08 \\
\hline Establishment of diagnosis & $18(10)$ & $19(9)$ & $18(11)$ & 0.89 \\
\hline Pharmaceutical recommendations & $34(21)$ & $32(21)$ & $38(24)$ & 0.39 \\
\hline Psychosocial and psychotherapeutic recommendations & $17(9)$ & $17(9)$ & $16(9)$ & 0.49 \\
\hline Orientation in the health service network & $12(8)$ & $11(12)$ & $15(8)$ & 0.39 \\
\hline Other ${ }^{b}$ & $2(12)$ & $3(14)$ & $0(1)$ & 0.47 \\
\hline $\begin{array}{l}\text { With clinicians in mental health (MH) primary care teams (MH-PCT) with whom } \\
\text { SRP worked (N (\%)): }\end{array}$ & $93(74)^{a}$ & $69(73)^{a}$ & $24(75)^{a}$ & \\
\hline Information on MHD & $19(22)$ & $16(20)$ & $31(25)$ & 0.04 \\
\hline Establishment of a diagnosis & $12(13)$ & $12(14)$ & $12(10)$ & 0.94 \\
\hline Pharmaceutical recommendations & $8(9)$ & $7(9)$ & $5(7)$ & 0.47 \\
\hline Psychosocial and psychotherapeutic recommendations & $46(35)$ & $47(37)$ & $37(25)$ & 0.34 \\
\hline Orientations in the health service network & $14(17)$ & $17(13)$ & $15(11)$ & 0.74 \\
\hline Other $^{b}$ & $1(4)$ & $1(5)$ & $0(0)$ & 0.51 \\
\hline With clinicians in one-stop MH service teams with whom SRP worked (N (\%)): & $89(71)^{\mathrm{a}}$ & $68(72)^{a}$ & $21(66)^{a}$ & \\
\hline Information on MHD & $13(13)$ & $12(13)$ & $18(15)$ & 0.13 \\
\hline Establishment of a diagnosis & $12(12)$ & $11(11)$ & $17(16)$ & 0.15 \\
\hline Pharmaceutical recommendations & $10(12)$ & $12(12)$ & $8(10)$ & 0.35 \\
\hline Psychosocial and psychotherapeutic recommendations & $19(18)$ & $18(19)$ & $20(15)$ & 0.76 \\
\hline Orientations in the health service network & $44(33)$ & $45(35)$ & $37(22)$ & 0.45 \\
\hline Other ${ }^{b}$ & $2(9)$ & $2(10)$ & $0(0)$ & 0.52 \\
\hline With clinicians in youth centers with whom SRP worked (N (\%)): & $15(12)^{a}$ & $1(1)^{a, c}$ & $14(44)^{\mathrm{a}}$ & \\
\hline Information on MHD & $20(6)$ & $15(15)$ & $21(23)$ & 0.35 \\
\hline Establishment of a diagnosis & $22(8)$ & $14(14)$ & $23(12)$ & 0.32 \\
\hline Pharmaceutical recommendations & $15(7)$ & $13(13)$ & $15(10)$ & 0.79 \\
\hline Psychosocial and psychotherapeutic recommendations & $22(7)$ & $18(18)$ & $23(7)$ & 0.54 \\
\hline Orientations in the health service network & $20(6)$ & $32(32)$ & $19(10)$ & 0.03 \\
\hline Other ${ }^{b}$ & $1(2)$ & $8(8)$ & $0(0)$ & \\
\hline
\end{tabular}

${ }^{a}$ Corresponds to the number of participants ( $\mathrm{n}$ ) and percentages (\%)

${ }^{b}$ Other: This can include for example administrative activities, discussions on the functioning of team meetings; ongoing feedback, discussions on interview methods or review of clinical records

' As there was only one SRP in adult psychiatry who worked with youth centers, we didn't introduced a comparison

* ANOVA t-test $p$ value

SRP had affiliations or had previously collaborated. Overall, GP were viewed as having little interest in SRP consultation, preferring that SRP consult directly with their patients and providing them with brief orientation. SRP were more successful when targeting "university" family medicine groups, whose training objectives involving medical residents coincided with SRP case discussions. Regarding youth centers, there was usually close collaboration with child-adolescent psychiatry departments, although few managers mentioned that SRP had much contact with them. SRP targeted specialized psychosocial clinicians in youth centers working with patients whose $\mathrm{MH}$ conditions were more serious and complex.

\section{Comfort, motivation, and satisfaction among SRP (questionnaire data, 5-point scales)}

SRP comfort and motivation related to their function and capacity to support primary care or youth centers were evaluated as good (3.7/5) (Table 3). SRP evaluated the complexity of their interventions as medium (3.3). They were very satisfied with their degree of influence in decision-making regarding patient referrals and choice 
Table 3 Comfort, motivation and satisfaction related to the function of specialist respondent psychiatrists (SRP)

\begin{tabular}{|c|c|c|c|c|}
\hline & $\begin{array}{l}\text { Total }(n=126) \\
\text { Mean }(S D)^{a}\end{array}$ & $\begin{array}{l}\text { Adult } \\
\text { psychiatry } \\
(n=94) \\
\text { Mean (SD) }\end{array}$ & $\begin{array}{l}\text { Child-adolescent } \\
\text { psychiatry } \\
(n=32) \\
\text { Mean (SD) }\end{array}$ & $P \_$value* \\
\hline a) Comfort and motivation related to the SRP function: & $3.70(0.52)$ & $3.64(0.52)$ & $3.86(0.49)$ & 0.04 \\
\hline Level of confidence in SRP capacity to support primary care & $3.96(0.73)$ & $3.90(0.67)$ & $4.13(0.87)$ & 0.14 \\
\hline Level of motivation for the function & $3.84(0.83)$ & $3.78(0.85)$ & $4.03(0.74)$ & 0.13 \\
\hline Level of complexity regarding interventions to which SRP respond & $3.30(0.58)$ & $3.26(0.58)$ & $3.44(0.56)$ & 0.12 \\
\hline \multicolumn{5}{|l|}{ Satisfaction with the SRP role } \\
\hline b) In relation to the function of SRP: & $3.79(0.65)$ & $3.72(0.62)$ & $4.00(0.71)$ & 0.04 \\
\hline Clarity of the role/mandate of SRP & $3.83(0.87)$ & $3.72(0.86)$ & $4.16(0.84)$ & 0.01 \\
\hline Clarity of civil responsibility related to SRP function & $3.44(1.07)$ & $3.31(1.05)$ & $3.81(1.06)$ & 0.02 \\
\hline Number of hours allocated for adequately carrying out SRP mandate & $3.67(0.96)$ & $3.63(0.96)$ & $3.81(0.96)$ & 0.35 \\
\hline Margin of maneuver for accomplishing SRP work adequately & $3.62(1.01)$ & $3.49(1.03)$ & $4.00(0.84)$ & 0.01 \\
\hline $\begin{array}{l}\text { Degree of influence in choice of appropriate therapeutic interventions - re: } \\
\text { cases discussed }\end{array}$ & $4.01(0.88)$ & $4.01(0.87)$ & $4.00(0.91)$ & 0.95 \\
\hline $\begin{array}{l}\text { Degree of influence in decision-making regarding patient orientation - re: cases } \\
\text { discussed }\end{array}$ & $4.17(0.82)$ & $4.16(0.79)$ & $4.22(0.90)$ & 0.72 \\
\hline c) In relation to support obtained for the SRP function in their organization: & $2.76(0.78)$ & $2.72(0.79)$ & $2.88(0.74)$ & 0.34 \\
\hline Administrative and logistical support provided by the organization & $2.90(1.22)$ & $2.73(1.20)$ & $3.38(1.15)$ & 0.01 \\
\hline Support for training activities on the SRP function & $2.45(1.00)$ & $2.39(1.07)$ & $2.59(0.79)$ & 0.33 \\
\hline $\begin{array}{l}\text { Feedback on the SRP role aimed at improving SRP functioning and effective- } \\
\text { ness }\end{array}$ & $2.70(1.23)$ & $2.70(1.31)$ & $2.69(0.96)$ & 0.95 \\
\hline $\begin{array}{l}\text { Optimal support for deployment of the SRP function by psychiatrists from their } \\
\text { organization }\end{array}$ & $3.07(1.01)$ & $3.09(1.04)$ & $3.03(0.94)$ & 0.79 \\
\hline Opportunities for exchanges with other SRP & $3.10(1.33)$ & $3.04(1.33)$ & $3.28(1.32)$ & 0.38 \\
\hline \multicolumn{5}{|l|}{ d) In relation to collaboration with targeted clinicians: } \\
\hline Adherence to the function with: & $3.63(1.18)$ & $3.43(1.58)$ & $3.86(1.25)$ & 0.40 \\
\hline General practitioners (GP) in family medicine groups & $3.34(0.99)$ & $3.38(0.96)$ & $3.20(1.08)$ & 0.43 \\
\hline Clinicians in mental health $(\mathrm{MH})$ primary care teams $(\mathrm{MH}-\mathrm{PCT})$ & $3.77(1.30)$ & $3.54(1.41)$ & $4.37(0.68)$ & 0.00 \\
\hline Clinicians in one-stop MH service teams & $3.93(1.13)$ & $3.82(1.23)$ & $4.27(0.63)$ & 0.10 \\
\hline Clinicians in youth centers & $3.48(1.31)$ & $3.00(1.81)$ & $3.61(1.14)$ & 0.36 \\
\hline Pertinence of consultations/collaborations with: & $3.99(0.97)$ & $3.96(1.04)$ & $4.07(0.91)$ & 0.70 \\
\hline GP in family medicine groups & $3.65(0.97)$ & $3.64(0.93)$ & $3.68(1.14)$ & 0.85 \\
\hline Clinicians in MH-PCT & $4.04(1.01)$ & $3.93(1.08)$ & $4.33(0.73)$ & 0.07 \\
\hline Clinicians in MH one-stop service teams & $4.20(0.79)$ & $4.19(0.81)$ & $4.23(0.75)$ & 0.85 \\
\hline Clinicians in youth centers & $4.07(1.14)$ & $4.11(1.36)$ & $4.06(1.05)$ & 0.90 \\
\hline $\begin{array}{l}\text { Stability of professionals with whom SRP interacted (all those mentioned } \\
\text { above) in the context of their function as SRP }\end{array}$ & $3.44(1.09)$ & $3.41(1.08)$ & $3.53(1.16)$ & 0.60 \\
\hline
\end{tabular}

a: 5 -point scale: $1=$ Very unsatisfied; $2=$ Unsatisfied; $3=$ Moderately satisfied; $4=$ Satisfied; $5=$ Very satisfied

${ }^{*}$ ANOVA t-test $p$ value

of therapeutic interventions $(4+)$, but less so regarding the clarity of their civil responsibility (3.4). They rated the relevance of their collaboration/consultations as high $(4+)$, except for GP consultations which were less satisfying (3.6). Satisfaction among SRP regarding the support offered by their organizations was low (2.8) in terms of training activities, feedback on SRP effectiveness or help forthcoming for administrative and logistical tasks. SRP working in child-adolescent psychiatry were significantly more comfortable and motivated around their overall functions than their counterparts in adult psychiatry (3.9 vs 3.6), including the clarity of their role/mandate (4.0 vs 3.7 ), civil responsibility ( 3.8 vs 3.3 ) and their margin of maneuver for accomplishing tasks adequately ( $4.0 \mathrm{vs} 3.5)$. SRP in child-adolescent psychiatry were also significantly more satisfied with both the administrative and logistical support provided by their organizations (3.4 vs 2.7 ) and 
with requests from MH-PCT for their services (4.4 vs 3.5).

\section{Profiles of patients discussed or seen in the context of SRP functions (questionnaire data)}

Overall, SRP patients were 18-30 years old, single, widowed or divorced and with low income (Table 4). They were mainly affected by common MHD (e.g. depressive disorders), followed by personality and substance-related disorders. Regarding service use, SRP estimated that $67 \%$ had a family doctor, and few used MH community organizations, addiction rehabilitation centers or private psychologists. Patient referral to specialized services was justified by severity or complexity of MHD and need for direct and regular psychiatrist intervention.

Compared with patients consulted in primary care or youth centers by SRP in child-adolescent psychiatry, those consulted by SRP in adult psychiatry were generally older, living with a spouse/common-law partner and with low income. They were significantly more affected by depressive, bipolar, psychotic, personality or substancerelated disorders, or had experienced a second MHD episode, while less affected by adjustment or attention deficit disorders with/without hyperactivity or other MHD. Work or housing problems, chronic physical illnesses and social isolation were also prevalent, but risk of aggressivity was lower. Moreover, adult patients received more services from addiction rehabilitation centers and were less likely to be followed by MH-PCT or youth centers. SRP in adult psychiatry also referred significantly more patients to specialized services for co-occurring MHDsubstance-related disorders, but also encountered more patients who refused referral to specialized services.

\section{Barriers or facilitators to effectiveness of the SRP function based on manager interviews}

Verbatim from the qualitative findings illustrates the main system-level, organizational, and individual barriers/facilitators to the deployment of the SRP function (see Additional file 2). Managers identified slightly more barriers than facilitators, mostly organization-related, followed closely by system-level, then individual factors. Major organizational barriers included instability or frequent MH-PCT staff turnover, but to a lesser degree in one-stop $\mathrm{MH}$ service teams (barrier identified by $40 \%$ of mangers - hereafter: "\% only"); lack of clinician involvement in MH-PCT meetings (30\%); insufficient SRP support from hospitals (25\%); insufficient coordination mechanisms between one-stop MH service teams, specialized care and SRP (25\%); and difficulty managing patients without family doctors in one-stop MH service teams (25\%). These patients could have been treated by GP in MH-PCT, had these teams recruited
GP or by SRP directly. For more rapid access to specialized care, patients often had to go through emergency departments. Many youth centers were also not prepared organizationally to accommodate SRP (20\%). Important organizational facilitators to the SRP function were: having a medical director supportive of SRP in family medicine groups, and interest in $\mathrm{MH}$ among psychosocial clinicians in those family medicine groups (30\%); working in university family medicine groups with teaching mandates aligned with SRP functions (30\%); networks with liaison nurses for care coordination between one-stop $\mathrm{MH}$ service teams and specialized care (25\%); adequate preparation of case discussions with SRP in MH-PCT (25\%); the possibility of referrals to specialized care and direct treatment by the SRP for patients not known to hospitals, optimizing the evaluation process (10\%); and in one-stop $\mathrm{MH}$ service teams, the provision of brief $\mathrm{MH}$ interventions to patients waiting for transfer to either MH-PCT or specialized care (10\%).

The main system-level barriers reported were network size and complexity, as when SRP had to travel long distances for team meetings (Web training was not allowed), when the SRP function covered two networks in "borderline" areas or included networks with a large volume of underprivileged patients with complex conditions (60\%). Another issue was lack of human resources, especially for psychiatrists working outside the Montreal and Quebec City networks, or where SRP networks were not viewed as a priority but as "icing on the cake" (50\%). The inflexibility of the consultation-liaison model particularly in relation to GP needs and modes of remuneration was evaluated as another key barrier (45\%). As SRP consultations were organized at regular intervals (e.g. the first Monday of each month), certain GP working at multiple settings were never able to attend. Office space for SRP working in clinics was sometimes problematic. As well, GP paid on a fee-for-service basis generally declined to spend several hours consulting with SRP on "other cases", preferring brief and immediate responses to their urgent patient needs. Other reported barriers were difficulties distinguishing between MHD appropriate to MH-PCT teams, GP only or specialized care (25\%), criteria that could vary according to network expertise and resource availability. Evaluations suggested that SRP spent too much time on MH-PCT consultations (10\%) relative to other providers, mostly GP; and that SRP were being highly paid for a service that would otherwise be integrated in their regular practice $(10 \%)$. Findings identified as main system-level facilitators were: pre-existing relationships with PCT (60\%); working in the same hospital as the SRP, more often the case for pediatricians and some MH-PCT (35\%); sharing the same electronic medical patient records, which was more characteristic 
Table 4 Profiles of patients discussed or seen by specialist respondent psychiatrists (SRP)

\begin{tabular}{|c|c|c|c|c|}
\hline Variables & $\begin{array}{l}\text { Total }(n=126) \\
\text { Mean (SD) }\end{array}$ & $\begin{array}{l}\text { Adult } \\
\text { psychiatry } \\
(n=94) \\
\text { Mean (SD) }\end{array}$ & $\begin{array}{l}\text { Child-adolescent } \\
\text { psychiatry } \\
(n=32) \\
\text { Mean (SD) }\end{array}$ & $P \_$value* \\
\hline \multicolumn{5}{|l|}{ Patient profile in percentages: } \\
\hline \multicolumn{5}{|l|}{ a) Sociodemographic data: } \\
\hline \multicolumn{5}{|l|}{ Age } \\
\hline $18-30$ years & $50.99(32.16)$ & $34.31(16.82)$ & 100 & 0.00 \\
\hline $31-64$ years & $37.20(25.79)$ & $49.86(15.99)$ & 0 & 0.00 \\
\hline $65+$ years & $11.81(12.64)$ & $15.83(12.27)$ & 0 & 0.00 \\
\hline \multicolumn{5}{|l|}{ Marital status } \\
\hline Single, widowed or divorced & $61.59(24.21)$ & $52.66(14.75)$ & $87.81(27.56)$ & 0.00 \\
\hline Married or with partner & $38.41(24.21)$ & $47.34(14.75)$ & $12.19(27.56)$ & 0.00 \\
\hline \multicolumn{5}{|l|}{ Income level } \\
\hline High & $15.86(20.80)$ & $11.63(8.78)$ & $28.28(36.04)$ & 0.00 \\
\hline Average & $37.27(18.39)$ & $38.31(16.49)$ & $34.22(23.14)$ & 0.27 \\
\hline Low & $46.87(21.13)$ & $50.06(18.62)$ & $37.50(25.27)$ & 0.00 \\
\hline b) Mental health disorders $(M H D)^{\mathrm{a}}$ : & Mean (SD) & Mean (SD) & Mean (SD) & $P \_$value* \\
\hline Common MHD & $92.73(47.54)$ & $91.61(48.54)$ & $96.04(45.66)$ & 0.34 \\
\hline Adjustment disorders & $20.91(19.07)$ & $19.98(18.24)$ & $23.66(21.38)$ & 0.00 \\
\hline Generalized anxiety & $25.17(16.87)$ & $25.93(18.46)$ & $22.97(10.91)$ & 0.39 \\
\hline Depressive disorders & $26.60(17.68)$ & $31.99(16.65)$ & $10.78(9.07)$ & 0.00 \\
\hline Attention deficit disorders with/without hyperactivity & $20.05(21.11)$ & $13.72(15.56)$ & $38.63(24.36)$ & 0.00 \\
\hline Severe MHD & $15.43(10.63)$ & $18.87(10.60)$ & $5.33(6.55)$ & 0.00 \\
\hline Bipolar disorders & $7.10(8.30)$ & $8.86(8.85)$ & $1.96(2.38)$ & 0.00 \\
\hline Psychotic disorders (e.g. schizophrenia, delirium) & $8.33(10.41)$ & $10.01(11.28)$ & $3.37(4.58)$ & 0.00 \\
\hline Personality disorders & $29.50(20.01)$ & $33.69(19.36)$ & $17.19(17.20)$ & 0.00 \\
\hline Substance-related disorders (SRD) & $29.53(27.15)$ & $34.51(24.56)$ & $14.93(29.45)$ & 0.00 \\
\hline Alcohol use disorders & $13.27(12.79)$ & $15.90(10.91)$ & $5.54(14.83)$ & 0.00 \\
\hline Drug use disorders & $16.26(16.33)$ & $18.60(15.88)$ & $9.39(15.92)$ & .01 \\
\hline Other (e.g. eating disorders, pain disorders, intellectual disability) & $19.44(22.64)$ & $15.72(18.49)$ & $30.36(29.61)$ & 0.00 \\
\hline MHD severity & $97.61(15.30)$ & $97.87(14.50)$ & $96.87(17.67)$ & 0.72 \\
\hline MHD $1^{\mathrm{e}}$ episode & $32.08(25.23)$ & $25.74(17.30)$ & $51.53(34.02)$ & 0.00 \\
\hline MHD $2^{e}$ episode & $32.89(18.51)$ & $37.41(16.53)$ & $19.59(17.82)$ & 0.00 \\
\hline Chronic MHD & $32.44(34.71)$ & $34.71(19.77)$ & $25.75(32.40)$ & 0.06 \\
\hline c) Other clinical dimensions (not required to equal $100 \%$ ) & Mean (SD) & Mean (SD) & Mean (SD) & $P_{-}$value* \\
\hline High suicide risk & $14.33(14.10)$ & $14.11(13.94)$ & $15.00(14.75)$ & 0.75 \\
\hline High risk for aggressiveness & $11.79(13.17)$ & $8.31(8.64)$ & $22.03(18.17)$ & 0.00 \\
\hline Housing problems (e.g. homelessness, poor housing) & $10.51(14.38)$ & $11.94(12.69)$ & $6.31(18.06)$ & 0.05 \\
\hline Work problems (e.g. loss of employment) & $25.42(22.09)$ & $33.20(19.62)$ & $2.56(9.49)$ & 0.00 \\
\hline Problems with activities of daily living & $31.02(21.57)$ & $29.60(20.40)$ & $35.22(24.55)$ & 0.20 \\
\hline Chronic physical illnesses & $18.75(17.02)$ & $24.00(16.50)$ & $3.34(4.77)$ & 0.00 \\
\hline Social isolation & $24.78(21.34)$ & $29.26(22.00)$ & $11.63(12.02)$ & 0.00 \\
\hline d) Service use (not required to equal 100\%): & Mean (SD) & Mean (SD) & Mean (SD) & $P_{-}$value* \\
\hline Having a family doctor & $66.61(26.92)$ & $68.78(25.60)$ & $60.31(30.02)$ & 0.12 \\
\hline Seeing a private psychologist & $10.97(9.97)$ & $11.36(9.89)$ & $9.81(10.28)$ & 0.45 \\
\hline Seeing a clinician in a MH team & $33.56(30.75)$ & $25.23(25.61)$ & $58.00(31.94)$ & 0.00 \\
\hline Using one or more $\mathrm{MH}$ community organizations & $15.49(15.49)$ & $15.97(13.76)$ & $14.09(19.92)$ & 0.55 \\
\hline Receiving services from addiction centers & $11.98(10.56)$ & $13.46(8.95)$ & $7.64(13.53)$ & 0.01 \\
\hline Being followed by youth centers & $8.76(19.44)$ & $1.93(10.55)$ & $28.84(25.14)$ & 0.00 \\
\hline
\end{tabular}


Table 4 (continued)

\begin{tabular}{|c|c|c|c|c|}
\hline Variables & $\begin{array}{l}\text { Total }(n=126) \\
\text { Mean (SD) }\end{array}$ & $\begin{array}{l}\text { Adult } \\
\text { psychiatry } \\
(n=94) \\
\text { Mean (SD) }\end{array}$ & $\begin{array}{l}\text { Child-adolescent } \\
\text { psychiatry } \\
(n=32) \\
\text { Mean (SD) }\end{array}$ & $P_{-}$value* \\
\hline $\begin{array}{l}\text { Qualifying as high users of } \mathrm{MH} \text { services (e.g. frequent emergency room use for } \\
\text { MH reasons }>3 \text { per year, multiple hospitalizations per year) }\end{array}$ & $14.43(14.99)$ & $14.71(13.75)$ & $13.60(18.38)$ & 0.72 \\
\hline $\begin{array}{l}\text { e) Criteria justifying orientation of patients toward } M H \text { specialized services ( } 5 \text { - } \\
\text { point scale: } 1=\text { Never; } 2=\text { Rarely; } 3=\text { Moderately often; } 4=\text { Often; } 5=\text { Very } \\
\text { often): }\end{array}$ & Mean (SD) & Mean (SD) & Mean (SD) & P_value* \\
\hline MHD too complex or too severe & $3.49(.97)$ & $3.54(.94)$ & $3.34(.97)$ & 0.31 \\
\hline Co-occurring MHD and SRD too complex or too severe & $2.90(.86)$ & $3.08(.79)$ & $2.37(.85)$ & 0.00 \\
\hline $\begin{array}{l}\text { The primary care team has exhausted all intervention avenues, and none have } \\
\text { worked }\end{array}$ & $2.82(.72)$ & $2.80(.73)$ & $2.89(.68)$ & 0.55 \\
\hline Needing direct and regular interventions by a psychiatrist & $3.13(.92)$ & $3.06(.88)$ & $3.06(1.04)$ & 0.61 \\
\hline Needing services offered by specialized MH services & $3.02(1.00)$ & $3.01(.97)$ & $3.03(1.07)$ & 0.80 \\
\hline $\begin{array}{l}\text { Patients should be referred to specialized MH services, but refuse for various } \\
\text { reasons including fear of stigma }\end{array}$ & $2.00(.81)$ & $2.25(.78)$ & $1.73(.78)$ & 0.00 \\
\hline
\end{tabular}

a Patients may have more than one mental disorder - total percentage may exceed 100\%

*ANOVA t-test $p$ value

in network hospitals and local community health service centers where MH-PCT and one-stop MH service teams were situated than in family medicine groups that had a separate electronic system (20\%); and the optimization of patient treatment (10\%). It was thought that the SRP could discuss four cases in the time required by a psychiatrist to complete one patient consultation.

Individual-level barriers related to the reluctance of many GP to treat patients with MHD (40\%); discomfort among SRP toward evaluating patients with whom they had not consulted directly, impacting on their civil responsibility (30\%); and the delay between GP calls to SRP and their responses which tended to come in the same day, whereas GP often wanted an immediate response (15\%). The individual qualities of SRP, their accessibility, sympathetic approach, openness to different practices, knowledge of network resources, and ability to work collaboratively and deal with crises were major facilitators (50\%). The ideal SRP would need to be a psychiatrist "champion" to ensure success of this function. Other facilitators were the leadership ability of the head network psychiatrist in supporting the SRP function or ensuring that the SRP function aligned well with main departmental service orientations (30\%), and awareness that $\mathrm{MH}-\mathrm{PCT}$ and one-stop MH service teams consisted of highly respected, senior clinicians.

\section{Perceived impacts of the SRP function according to SRP self-evaluation (questionnaire data, 5 -point scale)}

Overall, SRP rated the impacts of their function as moderate (Table 5). They ascribed high impact $(4.0+)$ only in terms of their ability to perform patient evaluations, particularly through MH-PCT, as well as their coordination and orientation of patients with specialized services, notably for MH-PCT and for one-stop MH services in child-adolescent psychiatry. SRP evaluated their impacts as low (2.0-2.9) on improving the ability of GP to establish a diagnosis, prescribe and orient patients with substance-related disorders toward counseling and psychotherapy. SRP also acknowledged their lack of impacts on the quantity of patients treated by GP or MH-PCT, on timeliness and effectiveness in treating patients referred by youth centers, and on their capacity to increase the supply of MH services in the networks.

SRP in child-adolescent psychiatry were significantly more positive than those in adult psychiatry concerning the overall impacts of their function (3.2 vs 2.8 ) in improving patient health and well-being (3.6 vs 3.1), integrating and promoting fluidity between primary care and specialized services (3.7 vs 3.2 ), and responding adequately to patient needs for service (3.8 vs 3.4 ). They were also significantly more confident that their function had improved the capacity of MH-PCT to evaluate (4.0 vs 3.4) and treat (3.9 vs 3.4) patients, the capacity of MH-PCT and one-stop $\mathrm{MH}$ service teams to coordinate with primary care ( 3.9 vs $3.3 ; 4.1$ vs 3.4$)$ and specialized care (4.2 vs $3.4 ; 4.2$ vs 3.6 ), and coordination between $\mathrm{MH}-\mathrm{PCT}$ and addiction rehabilitation centers (3.9 vs 3.3). They also viewed themselves as having significantly improved the capacity of one-stop MH service teams to orienting patients toward appropriate services (4.0 vs 3.3). GP improvement in pharmacological treatment was the only area where SRP working in adult psychiatry rated their 
Table 5 Impact of the specialist respondent psychiatrist (SRP) function on service improvement

\begin{tabular}{|c|c|c|c|c|}
\hline Improvement: & Total $(n=126)$ & $\begin{array}{l}\text { Adult } \\
\text { psychiatry } \\
(n=94)\end{array}$ & $\begin{array}{l}\text { Child-adolescent } \\
\text { psychiatry }(n=32)\end{array}$ & P_value* \\
\hline Of the followed activities: & Mean $^{\mathrm{a}}(\mathrm{SD})$ & Mean $^{\mathrm{a}}(\mathrm{SD})$ & $\operatorname{Mean}^{\mathrm{a}}(\mathrm{SD})$ & \\
\hline Ability of general practitioners (GP) to establish a diagnosis & $2.95(0.87)$ & $3.01(0.88)$ & $2.74(0.81)$ & 0.15 \\
\hline Pharmacological treatment by GP & $3.39(0.86)$ & $3.47(0.82)$ & $3.110(.93)$ & 0.05 \\
\hline $\begin{array}{l}\text { Prescribing and orientation toward counseling and psychotherapy for mental health } \\
\text { disorders (MHD) by GP }\end{array}$ & $3.25(0.91)$ & $3.34(0.86)$ & $2.96(1.01)$ & 0.06 \\
\hline $\begin{array}{l}\text { Prescribing and orientation toward counseling and psychotherapy for substance-related } \\
\text { disorders (SRD) by GP }\end{array}$ & $2.97(0.87)$ & $3.03(0.83)$ & $2.76(0.97)$ & 0.16 \\
\hline \multicolumn{5}{|l|}{ In the ability of these services to evaluate a patient } \\
\hline MH primary care teams (MH-PCT) & $3.58(0.98)$ & $3.410 .97)$ & $4.04(0.85)$ & 0.00 \\
\hline One-stop MH service teams & $3.53(0.82)$ & $3.53(0.80)$ & $3.53(0.90)$ & 0.98 \\
\hline Youth centers & $3.74(0.99)$ & $4.50(0.70)$ & $3.65(0.99)$ & 0.26 \\
\hline \multicolumn{5}{|l|}{ In the quality of patient treatment by } \\
\hline GP & 0 & $3.25(0.85)$ & $3.26(0.94)$ & 0.95 \\
\hline MH-PCT & $3.52(0.98)$ & $3.35(0.96)$ & $3.93(0.90)$ & 0.01 \\
\hline \multicolumn{5}{|l|}{ In the quantity of patients treated by } \\
\hline GP & $2.97(0.93)$ & $3.01(0.90)$ & $2.85(1.04)$ & 0.43 \\
\hline MH-PCT & $3.09(1.14)$ & $2.96(1.11)$ & $3.44(1.19)$ & 0.07 \\
\hline \multicolumn{5}{|l|}{ In timeliness and effectiveness of patient treatment requested by } \\
\hline One-stop MH service teams & $3.41(0.91)$ & $3.38(0.96)$ & $3.50(0.85)$ & 0.64 \\
\hline Youth centers & $3.25(1.15)$ & $2.88(1.45)$ & $3.44(0.96)$ & 0.26 \\
\hline \multicolumn{5}{|l|}{ In coordination with MH primary care services } \\
\hline GP & $3.34(1.08)$ & $3.30(1.08)$ & $3.44(1.12)$ & 0.58 \\
\hline MH-PCT & $3.43(1.08)$ & $3.25(1.01)$ & $3.89(1.15)$ & 0.00 \\
\hline One stop MH service teams & $3.54(0.97)$ & $3.39(0.99)$ & $4.05(0.70)$ & 0.00 \\
\hline Youth centers & $3.46(0.90)$ & $3.13(0.83)$ & $3.61(0.91)$ & 0.21 \\
\hline \multicolumn{5}{|l|}{ In coordination with specialized MH services } \\
\hline GP & $3.34(1.10)$ & $3.30(1.08)$ & $3.44(1.12)$ & 0.58 \\
\hline MH-PCT & $3.65(1.05)$ & $3.44(1.07)$ & $4.18(0.81)$ & 0.00 \\
\hline One stop MH service teams & $3.72(0.88)$ & $3.59(0.87)$ & $4.16(0.76)$ & 0.01 \\
\hline Youth centers & $3.69(1.05)$ & $3.13(1.12)$ & $3.94(0.93)$ & 0.06 \\
\hline \multicolumn{5}{|l|}{ In the capacity to orient patients toward appropriate services } \\
\hline GP & $3.40(1.00)$ & $3.39(0.98)$ & $3.44(1.08)$ & 0.80 \\
\hline MH-PCT & $3.29(1.04)$ & $3.20(1.00)$ & $3.52(1.12)$ & 0.19 \\
\hline One stop MH service teams & $3.44(0.99)$ & $3.28(1.02)$ & $4.00(0.66)$ & 0.00 \\
\hline Youth centers & $3.58(1.04)$ & $3.50(1.06)$ & $3.61(0.91)$ & 0.78 \\
\hline \multicolumn{5}{|l|}{ In the capacity to orient patients toward appropriate services for SRD } \\
\hline MH-PCT & $3.43(1.08)$ & $3.25(1.01)$ & $3.89(1.15)$ & 0.01 \\
\hline One stop MH service teams & $3.40(0.91)$ & $3.39(0.92)$ & $3.41(0.87)$ & 0.94 \\
\hline Youth centers & $3.22(0.99)$ & $2.75(0.70)$ & $3.47(1.06)$ & 0.10 \\
\hline Overall impact of the SRP function & $3.22(0.85)$ & $3.130(.81)$ & $3.49(0.91)$ & 0.04 \\
\hline Increase of MH services offered in the network & $2.87(1.21)$ & $2.77(1.18)$ & $3.16(1.27)$ & 0.11 \\
\hline Improvement in patient access to services & $3.10(1.07)$ & $3.06(1.09)$ & $3.22(1.03)$ & 0.48 \\
\hline Improvement in the adequacy of services for responding to patient needs & $3.48(1.03)$ & $3.36(1.03)$ & $3.81(0.96)$ & 0.03 \\
\hline Improvement in patient health and wellbeing & $3.24(0.96)$ & $3.11(0.95)$ & $3.62(0.90)$ & 0.01 \\
\hline $\begin{array}{l}\text { Capacity of SRP to support joint follow-up of patient by primary care and specialized } \\
\text { MH services }\end{array}$ & $3.37(1.02)$ & $3.30(0.93)$ & $3.56(1.24)$ & 0.20 \\
\hline $\begin{array}{l}\text { Better integration and fluidity of services between primary care and specialized MH } \\
\text { services }\end{array}$ & $3.32(0.94)$ & $3.18(1.10)$ & $3.72(.1 .14)$ & 0.02 \\
\hline
\end{tabular}

a: 5 -point scale: $1=$ No impact; $2=$ Weak impact; $3=$ Average impact; $4=$ High impact; $5=$ Very high impact

* ANOVA t-test 
impact as significantly more positive than that of their colleagues in child-adolescent psychiatry (3.5 vs 3.1).

\section{Discussion}

This study was original in focusing on the main activities of Quebec SRP and their impacts on the capacity of primary care providers (MH-PCT, one-stop MH service and GP) and youth centers to treat and orient patients with MHD. Little has been published on the perceptions of psychiatrists regarding the consultation-liaison model or on the SRP function, specifically in Quebec. Results showed that SRP were implemented sparingly in family medicine groups, while they viewed their overall impacts on the consolidation of primary care and youth centers as moderate. This was also the first study to compare the activities and impacts of SRP working in adult versus child-adolescent psychiatry, with more positive results for the SRP function in the latter.

While previous research estimated the total number of Quebec SRP at 446 [90], roughly half were not active in 2019-20. Our study response rate suggests that fewer than $25 \%$ of Quebec psychiatrists worked as active SRP for roughly 1 day a week. Their work focused on supporting either MH-PCT and one-stop MH services, or GP in family medicine groups. Few SRP services were developed in youth centers, and fewer still with GP as compared to MH-PCT and one-stop MH services. Overall, SRP have reached few GP, and the SRP function has not responded as well to their needs as other potential models of integrated $\mathrm{MH}$ services. For instance, the use of systematic psychiatric assessment, longitudinal monitoring and care management, as in the collaborative care model, may have better met the needs of GP and patients with MHD, yet these strategies were not included in the consultation-liaison model. As the main providers of $\mathrm{MH}$ services for common MHD and gatekeepers to other $\mathrm{MH}$ and social services [91, 92], GP might benefit more from the SRP function if they adhered more closely to the collaborative care model. Moreover, the SRP function focused more on consolidating services provided by onestop $\mathrm{MH}$ service teams as crucial for promoting service coordination between MH-PCT and specialized care and for reducing wait time for these services. Developed after 2007 in each Quebec network [67, 93], one-stop MH service teams with the assistance of SRP also aimed to help GP with treatment of patients with MHD, ensuring that only severe and complex cases were transferred to psychiatric care.

Regarding the main activities of SRP, the finding that patient consultation was the second-highest activity reported in terms of median hours per month for over half of SRP suggests that some SRP had incorporated this characteristic of the collaborative care model into their practices [60]. As the 2009 agreement stipulated that SRP could meet patients only exceptionally [66], this change seems to correlate with frequent GP requests that SRP assess their patients directly, bypassing lengthy wait times for accessing one-stop MH service teams or specialized care. The higher total hours per month provided by SRP in adult psychiatry compared with child-adolescent psychiatry can be easily explained by the higher number of primary care clinicians targeting adults for adequate coverage in each network. Both the SRP questionnaire and manager interviews outlined the underutilization of telephone/video availability by SRP between consultations with primary care clinicians or youth centers, and particularly in child-adolescent psychiatry where this service was nonexistent in most networks, mainly due to lack of psychiatrists or the inability of youth centers to coordinate with SRP. In terms of the main SRP activities delivered, the fact that SRP essentially provided GP with medication-related recommendations, $\mathrm{MH}-\mathrm{PCT}$ and youth centers with recommendations on psychosocial and psychotherapeutic treatments, and one-stop $\mathrm{MH}$ service teams with advice on service network orientation was not surprising, as SRP recommendations corresponded to key elements of the mandates under which these service providers operated.

Concerning the comfort level and motivation of SRP, dissatisfaction with the organizational support offered was invoked by both SRP and managers. Formal SRP meetings were rarely held, nor was training or feedback on their activities provided, which may explain the lack of uniformity in their practice. Regarding relationships between SRP and the various teams, their great comfort level with primary care teams but not GP suggests that their specialized expertise was viewed overall as complementary to that offered by psychosocial professionals. Moreover, MH-PCT and one-stop MH service teams consisted largely when created of former $\mathrm{MH}$ professionals from specialized services [67], whose positive collaboration with SRP was likely due to previous shared work experiences. Moreover, the greater motivation and comfort of SRP in child-adolescent psychiatry compared with adult SRP may be explained by their longstanding history of consultations in the community, a highly valued aspect of their practice as previously reported $[2,94]$.

Regarding the profiles of patients met or discussed by SRP, it was not surprising to find a preponderance of patients with low incomes and using few health services, much like patients overall seen in local community health service centers $[95,96]$. Moreover, the percentage with a family doctor $(67 \%)$ reported in the study was slightly inferior to that of the general Quebec population $(\sim 75 \%)$ [97]. SRP patients were also mainly affected by common MHD, corresponding to the profile usually targeted by 
shared care or collaborative care $[29,38]$. As well, the proportion of study patients with personality disorders or substance-related disorders was relatively high. GP and other primary care clinicians usually have limited time to treat and follow up such patients whose relationships with health services are often conflicted [98, 99]. Finally, diagnoses found mainly in child-adolescent psychiatry (adjustment disorders, attention deficit disorders with or without hyperactivity) were those that affected academic performance, social relationship and the safety of children and adolescents [100-103].

Regarding identified barriers/facilitators to the effectiveness of SRP activities, most concerned organizational-level issues. Team instability and frequent staff turnover led to the loss of skills and knowledge hardwon over time [55]. Lack of involvement in some teams may have reflected little interest in the model or doubts about its capacity to improve skills [61]. Regarding the difficulty of managing patients without family doctors, the 2005-2010 Quebec MH Action Plan [65] had recommended two GP per 100,000 inhabitants in MH-PCT, but this target had not been reached. Concerning systemrelated barriers/facilitators, the availability of appropriate resources [55], payments or incentives [57-59], and preexisting relationships between specialized $\mathrm{MH}$ services and other care providers [56] were reported in previous research as key to implementation of the model. Successful deployment of the consultation-liaison model is also impossible without adequate and sufficient human resources, including psychiatrists and GP working in MH-PCT throughout the networks [56, 104]. Not least, preexisting relationships are key to the intensity of collaboration necessary for successful implementation of this model [22]. Regarding individual-level barriers, the reluctance of some GP to embrace the SRP function was reported previously [25]. Discomfort among SRP in assuming joint liability with clinicians for patients not consulted directly by them was another source of discomfort previously reported in a Canadian study [22].

Regarding impacts of the SRP function, the perceived moderate impacts of SRP in this study on the ability of GP to establish a diagnosis, prescribe and orient patients with MHD toward counseling and psychotherapy as well as the quantity of patients treated ran counter to previous results $[30,51]$. Considering that the SRP model had little flexibility and seemed mostly unresponsive to GP needs, SRP continued to have difficulty appealing to GP, who too often showed little interest in treating patients with MHD in their current practices, had little time to discuss treatments with SRP and complained that SRP responses to their urgent questions came too late. By contrast, the longer history of collaboration with primary care and youth centers in child-adolescent psychiatry may account for the more positive impacts of SRP there [94]. Another possible explanation is that $\mathrm{MH}$ primary care services for children and adolescents in Quebec were less developed than adult services, where better results were attained. Some studies suggest that resource scarcity may encourage interorganizational and inter-professional collaboration $[105,106]$.

\section{Limitations}

Certain limitations in this study should be noted. First, the study did not investigate the impacts of SRP on patient outcomes. Second, the perspectives of GP and other primary care or youth center clinicians were not investigated. Third, the SRP response rate, while adequate for this type of research with medical doctors, could have been higher. Finally, the results may not be generalizable to other models of integrated MH services in primary care or to diverse $\mathrm{MH}$ systems.

\section{Conclusion}

Results suggested that the consultation-liaison model as implemented in Quebec since 2009 differed to some extent from what was initially planned, as evidenced in the time SRP dedicated to direct consultations with patients with or without other clinicians. Results also showed that SRP were generally motivated and comfortable in their function, notwithstanding lack of support from their organizations. Support for SRP needs to be increased in terms of integrating training programs, monitoring meetings, and sharing patient data among providers. Forums for regular professional support among SRP, tailored to their specific needs, are recommended, allowing them to exchange experiences and challenges, increase their comfort/motivation with the SRP function, and feel less isolated in their work. Such meetings could be organized with SRP in adult and child-adolescent psychiatry. Virtual SRP meetings should be encouraged particularly in isolated regions or in geographically extensive areas to promote more efficient collaboration. A standardized provincial guide on best practices for SRP, with particular focus on treating cases of MHD in primary care or specialized services, could be produced. More flexibility toward implementation of the model may also be advisable, as well as better adaptation of the model to territorial characteristics. SRP had a less positive impact on GP in family medicine groups, suggesting the need for increased adaptation of the model to meet GP needs. Perhaps the Quebec model may be more closely aligned with the collaborative care model, based on the generic Wager chronic care model, including the stepped-care approach. Other than modifying GP payment schemes to increase their motivation to collaborate with SRP, 
the orientations supported by $\mathrm{MH}$ reforms need to be better integrated with government directives regarding the consolidation of primary care. Lack of access to a family doctor for all citizens is another major issue that hampers the SRP function. Systemic problems, mainly professional instability, particularly in $\mathrm{MH}-\mathrm{PCT}$, long wait times for access to $\mathrm{MH}-\mathrm{PCT}$ and psychiatric care and the implementation of innovations especially for GP and youth centers should be tackled without delay. Better working conditions including incentives for personnel retention and adaptation of best practices are greatly needed. As well, wider deployment of liaison nurses working closely with SRP and their partners may improve coordination between primary care and specialized MH services. Regarding future research, it would be interesting to compare the perspectives of primary care clinicians with those of SRP and further investigate differences among SRP in terms of their profiles, work characteristics and impacts on primary care $\mathrm{MH}$ consolidation.

\section{Abbreviations}

GP: General practitioners; MH: Mental health; MHD: Mental health disorders; MH-PCT: Mental health primary care teams; SRP: Specialist respondent-psychiatrists.

\section{Supplementary Information}

The online version contains supplementary material available at https://doi. org/10.1186/s12875-021-01437-5.

\section{Additional file 1.}

Additional file 2. Sample quotations for specialist respondent-psychiatrist (SRP) managers: Main barriers (--) and facilitators $(++)$ to implementation of the SRP function.

\section{Acknowledgments}

We thank the individuals who participated in the research especially the specialist respondent-psychiatrists, the psychiatrist department heads or other clinician-managers interviewed, as well as the research team including our advisory committee made of key decision-makers who help with the study data collection. We would like to thank Armelle Imboua who coordinated this research project, and Judith Sabetti for editorial assistance.

\section{Authors' contributions}

MJF designed the overall research project and was responsible for the data collection. MJF, LG and GG designed analytical plan for the article. LG, GG and MJF wrote the article. LG produced the quantitative analyses and tables. PR revised the final version of the article. All authors read and approved the final manuscript.

\section{Funding}

This study was funded by the Canadian Institutes of Health Research (CIHR), grant number 8736. The funding agency had no further role in the study design, data analysis and interpretation, the dating of the manuscript or the decision to submit this article for publication.

\section{Availability of data and materials}

The datasets generated and analysed during the current are not publically available, signed confidentiality agreements preventing us from sharing the data, but are available from the corresponding author on reasonable request.

\section{Declarations}

\section{Ethics approval and consent to participate}

All procedures performed in this study involving human participants were in accordance with the ethical standards of the institutional committee and with the 1964 Helsinki declaration and its later amendments or comparable ethical standards. Ethics approval was provided by the research ethics board of the Douglas Mental Health University Institute (Project IUSMD \#16-45) and all participants provided informed consent.

\section{Consent for publication}

Not applicable.

\section{Competing interests}

The authors declared no competing interests.

\section{Author details}

${ }^{1}$ Department of Psychiatry, McGill University, Montreal, QC, Canada. ${ }^{2}$ Douglas Mental Health University Institute Research Center, Montréal, QC, Canada.

${ }^{3}$ Department of Family Medicine and Emergency Medicine, University of Sherbrooke, Sherbrooke, QC, Canada.

Received: 11 December 2020 Accepted: 6 April 2021

Published online: 29 April 2021

\section{References}

1. Eghaneyan BH, Sanchez K, Mitschke DB. Implementation of a collaborative care model for the treatment of depression and anxiety in a community health center: results from a qualitative case study. J Multidiscip Healthc. 2014;7:503-13. https://doi.org/10.2147/JMDH.S69821.

2. Sved-Williams A, Poulton J. Primary care mental health consultationliaison: a connecting system for private psychiatrists and general practitioners. Australas Psychiatry. 2010;18:125-9. https://doi.org/10. 3109/10398560903469783.

3. Lesage A, Vasiliadis H-M, Gagné M-A, Dudgeon S, Kasman N, Hay C. Prevalence of mental illness and related service utilization in Canada: an analysis of the Canadian Community Health Survey. Mississauga: Canadian Collaborative Mental Health Initiative; 2006.

4. Ouadahi Y, Lesage A, Rodrigue J, Fleury M-J. [Can mental health problems be diagnosed by general physicians? Perpectives of family physicians according to administrative standards]. Sante Ment Que. 2009:34:161-72.

5. Fleury MJ, Farand L, Aube D, Imboua A. Management of mental health problems by general practitioners in Quebec. Can Fam Physician. 2012;58(e732-738):e725-731.

6. Kontopantelis E, Olier I, Planner C, Reeves D, Ashcroft DM, Gask L, Doran T, Reilly S. Primary care consultation rates among people with and without severe mental illness: a UK cohort study using the Clinical Practice Research Datalink. BMJ Open. 2015;5:e008650. https://doi.org/10.1136/ bmjopen-2015-008650.

7. Rothman AA, Wagner EH. Chronic illness management: what is the role of primary care? Ann Intern Med. 2003;138:256-61. https://doi.org/10. 7326/0003-4819-138-3-200302040-00034

8. Kessler R. Mental health care treatment initiation when mental health services are incorporated into primary care practice. J Am Board Fam Med. 2012;25:255-9. https://doi.org/10.3122/jabfm.2012.02.100125.

9. Agyapong VI, Jabbar F, Conway C. Shared care between specialised psychiatric services and primary care: the experiences and expectations of general practitioners in Ireland. Int J Psychiatry Clin Pract. 2012;16:293-9. https://doi.org/10.3109/13651501.2012.667115.

10. Jego M, Debaty E, Ouirini L, Carrier H, Beetlestone E. Caring for patients with mental disorders in primary care: a qualitative study on French GPs views, atittudes and needs. Fam Pract. 2019;36:72-6. https://doi.org/10. 1093/fampra/cmy107.

11. Fleury MJ, Imboua A, Aube D, Farand L, Lambert Y. General practitioners' management of mental disorders: a rewarding practice with considerable obstacles. BMC Fam Pract. 2012;13:19. https://doi.org/10.1186/ 1471-2296-13-19. 
12. Fleury MJ, Bamvita JM, Aube D, Tremblay J. Clinical practice settings associated with GPs who take on patients with mental disorders. Healthc Policy. 2010;5:90-104.

13. Rehm J, Allamani A, Elekes Z, Jakubczyk A, Manthey J, Probst C, Struzzo P, Della Vedova R, Gual A, Wojnar M. Alcohol dependence and treatment utilization in Europe - a representative cross-sectional study in primary care. BMC Fam Pract. 2015;16:90. https://doi.org/10.1186/ s12875-015-0308-8.

14. Jacob B, Macquet D, Natalis S. [A global reform of mental health care based on a community approach: the Belgian experience]. Sante Ment Que. 2014;39:209-42.

15. Kisely S, Lesage A. [Mental health services in Australia]. Sante Ment Que. 2014;39:195-208.

16. Mental Health Commission of Canada. Building for the future- 20172018 annual report. Ottawa: Mental Health Commission of Canada; 2018

17. Aupont O, Doerfler L, Connor DF, Stille C, Tisminetzky M, McLaughlin TJ. A collaborative care model to improve access to pediatric mental health services. Adm Policy Ment Health. 2013;40:264-73. https://doi. org/10.1007/s10488-012-0413-0.

18. Bauer AM, Fielke K, Brayley J, Araya M, Alem A, Frankel BL, Fricchione GL. Tackling the global mental health challenge: a psychosomatic medicine/consultation-liaison psychiatry perspective. Psychosomatics. 2010;51:185-93. https://doi.org/10.1176/appi.psy.51.3.185.

19. Wagner E, Austin BT, Davis C, Hindmarsh M, Schaefer J, Bonomi A. Improving chronic illness care: translating evidence into action. Health Aff. 2001;20:64-78. https://doi.org/10.1377/hlthaff.20.6.64.

20. Kates N, McPherson-Doe C, George L. Integrating mental health services within primary care settings: the Hamilton Family Health Team. J Ambul Care Manage. 2011;34:174-82. https://doi.org/10.1097/JAC. Ob013e31820f6435.

21. Kisely $\mathrm{S}, \mathrm{Chisholm} \mathrm{P.} \mathrm{Shared} \mathrm{mental} \mathrm{health} \mathrm{care} \mathrm{for} \mathrm{a} \mathrm{marginalized}$ community in inner-city Canada. Australas Psychiatry. 2009;17:130-3. https://doi.org/10.1080/10398560802444044.

22. Kisely S, Campbell LA. Taking consultation-liaison psychiatry into primary care. Int J Psychiatry Med. 2007;37:383-91. https://doi.org/10. 2190/PM.37.4.C.

23. Huffman JC, Niazi SK, Rundell JR, Sharpe M, Katon WJ. Essential articles on collaborative care models for the treatment of psychiatric disorders in medical settings: a publication by the academy of psychosomatic medicine research and evidence-based practice committee. Psychosomatics. 2014:55:109-22. https://doi.org/10.1016/j.psym.2013.09.002.

24. Menchetti M, Tarricone I, Bortolotti B, Berardi D. Integration between general practice and mental health services in Italy: guidelines for consultation-liaison services implementation. Int J Integr Care. 2006;6:e05. https://doi.org/10.5334/ijic.152.

25. Fleury MJ, Grenier G, Robitaille D. Implementation of the consultationliaison model in Quebec and its impact on primary care providers. Ment Health Fam Med. 2016;12:228-40.

26. Meadows GN, Harvey CA, Joubert L, Barton D, Bedi G. Best practices: the consultation-liaison in primary-care psychiatry program: a structured approach to long-term collaboration. Psychiatr Serv. 2007:58:1036-8. https://doi.org/10.1176/appi.ps.58.8.1036.

27. Cape J, Whittington C, Bower P. What is the role of consultation-liaison psychiatry in the management of depression in primary care? A systematic review and meta-analysis. Gen Hosp Psychiatry. 2010;32:24654. https://doi.org/10.1016/j.genhosppsych.2010.02.003.

28. Emerson MR. Implementing a hybrid-collaborative care model: practical considerations for nurse practitioners. Issues Ment Health Nurs. 2019:40:112-7. https://doi.org/10.1080/01612840.2018.1524533.

29. Archer J, Bower P, Gilbody S, Lovell K, Richards D, Gask L, Dickens C, Coventry P. Collaborative care for depression and anxietyproblems. Cochrane Database Syst Rev. 2012;10:CD006525. https://doi.org/10. 1002/14651858.CD006525.pub2.

30. Gillies D, Buykx P, Parker AG, Hetrick SE. Consultation liaison in primary care for people with mental disorders. Cochrane Database Syst Rev. 2015;9:CD007193. https://doi.org/10.1002/14651858.CD007193.pub2.

31. Bauer MS, Miller CJ, Kim B, Lew R, Stolzmann K, Sullivan J, Riendeau R, Pitcock J, Williamson A, Connolly S, et al. Effectiveness of implementing a collaborative chronic care model for clinician teams on patient outcomes and health status in mental health: a randomized clinical trial. JAMA Netw Open. 2019;2:e190230. https://doi.org/10.1001/jaman etworkopen.2019.0230.

32. Hedrick SC, Chaney EF, Felker B, Liu CF, Hasenberg N, Heagerty P, Buchanan J, Bagala R, Greenberg D, Paden G, Fihn SD, Katon W. Effectiveness of collaborative care depression treatment in Veterans' Affairs primary care. J Gen Intern Med. 2003;18:9-16.

33. Katon W, Von Korff M, Lin E, et al. Collaborative management to achieve treatementguidlines. Impact on depression in primary care. JAMA. 1995:273:1026-31.

34. Katon W, von Korff M, Lin E, Simon G, Walker E, Unützer J, Bush T, Russo J, Ludman E. Stepped collaborative care for primary care patients with persistent symptoms of depression; a randomized trial. Arch Gen Psychiatry. 1999;56:1109-15. https://doi.org/10.1001/archpsyc.56.12.1109.

35. Copello A, Walsh K, Graham H, Tobin D, Griffith E, Day E, Birchwood M. A consultation-liaison service on integrated treatment: a program description. J Dual Diagn. 2013;9:149-57.

36. Camacho EM, Davies LM, Hann M, Small N, Bower P, Chew-Graham C, Baguely C, Gask L, Dickens CM, Lovell K, et al. Long-term clinical and cost-effectiveness of collaborative care (versus usual care) for people with mental-physical multimorbidity: cluster-randomised trial. $\mathrm{Br} J$ Psychiatry. 2018;213:456-63. https://doi.org/10.1192/bjp.2018.70.

37. Curth NK, Brinck-Claussen U, Jorgensen KB, Rosendal S, Hjorthoj C, Nordentoft M, Eplov LF. Collaborative care vs consultation liaison for depression and anxiety disorders in general practice: study protocol for two randomized controlled trials (the Danish Collabri Flex trials). Trials. 2019;20:607. https://doi.org/10.1186/s13063-019-3657-0.

38. Gilbody S, Lewis H, Adamson J, Atherton K, Bailey D, Birtwistle J, Bosanquet K, Clare E, Delgadillo J, Ekers D, et al. Effect of collaborative care vs usual care on depressive symptoms in older adults with subthreshold depression: the CASPER randomized clinical trial. JAMA. 2017;317:72837. https://doi.org/10.1001/jama.2017.0130.

39. Richards DA, Hill JJ, Gask L, Lovell K, Chew-Graham C, Bower P, Cape J, Pilling S, Araya R, Kessler D, et al. Clinical effectiveness of collaborative care for depression in UK primary care (CADET): cluster randomised controlled trial. BMJ. 2013;347:f4913. https://doi.org/10.1136/bmj.f4913.

40. Rollman BL, Herbeck Belnap B, Abebe KZ, Spring MB, Rotondi AJ, Rothenberger SD, Karp JF. Effectiveness of online collaborative care for treating mood and anxiety disorders in primary care: a randomized clinical trial. JAMA Psychiatry. 2018;75:56-64. https://doi.org/10.1001/ jamapsychiatry.2017.3379.

41. Coventry PA, Hudson JL, Kontopantelis E, Archer J, Richards DA, Gilbody S, Lovell K, Dickens C, Gask L, Waheed W, et al. Characteristics of effective collaborative care for treatment of depression: a systematic review and meta-regression of 74 randomised controlled trials. PLoS One. 2014;9:e108114. https://doi.org/10.1371/journal.pone.0108114.

42. Richardson LP, Ludman E, McCauley E, Lindenbaum J, Larison C, Zhou C, Clarke G, Brent D, Katon W. Collaborative care for adolescents with depression in primary care: a randomized clinical trial. JAMA. 2014;312:809-16. https://doi.org/10.1001/jama.2014.9259.

43. Bowen DJ, Powers DM, Russo J, Arao R, LePoire E, Sutherland E, Ratzliff $\mathrm{ADH}$. Implementing collaborative care to reduce depression for rural native American/Alaska native people. BMC Health Serv Res. 2020;20:34. https://doi.org/10.1186/s12913-019-4875-6.

44. Muntingh AD, van der Feltz-Cornelis CM, van Marwijk HW, Spinhoven $P$, van Balkom AJ. Collaborative care for anxiety disorders in primary care: a systematic review and meta-analysis. BMC Fam Pract. 2016;17:62 https://doi.org/10.1186/s12875-016-0466-3.

45. Cerimele JM, Halperin AC, Spigner C, Ratzliff A, Katon WJ. Collaborative care psychiatrists' views on treating bipolar disorder in primary care: a qualitative study. Gen Hosp Psychiatry. 2014;36:575-80. https://doi.org/ 10.1016/j.genhosppsych.2014.07.013.

46. Bauer MS, Weaver K, Kim B, Miller C, Lew R, Stolzmann K, Sullivan JL, Riendeau R, Connolly S, Pitcock J, et al. The collaborative chronic care model for mental health conditions: fromevidencesynthesis to policy impact to scale-up and spread. Med Care. 2019;57:S221-7. https://doi. org/10.1097/MLR.0000000000001145.

47. Reilly S, Planner C, Gask L, Hann M, Knowles S, Druss B, Lester H. Collaborative care approaches for people withsevere mental illness. Cochrane Database Syst Rev. 2013;11:CD009531. https://doi.org/10.1002/14651 858.CD009531.pub2. 
48. Baum RA, Manda D, Brown CM, Anzeljc SA, King MA, Duby J. A learning collaborative approach to improve mental health service delivery in pediatric primary care. Pediatr Qual Saf. 2018;3:e119. https://doi.org/10. 1097/pq9.0000000000000119.

49. Beers LS, Godoy L, John T, Long M, Biel MG, Anthony B, Mlynarski L, Moon R, Weissman M. Mental health screening quality improvement learning collaborative in pediatric primary care. Pediatrics. 2017; 140. https://doi.org/10.1542/peds.2016-2966.

50. Petersen I. Comprehensiveintegratedprimary mental health care for South Africa. Pipedream or possibility? Soc Sci Med. 2000;51:321-34. https://doi.org/10.1016/s0277-9536(99)00456-6.

51. Butler DJ, Fons D, Fisher T, Sanders J, Bodenhamer S, Owen JR, Gunderson $\mathrm{M}$. A review of the benefits and limitations of a primary careembedded psychiatric consultation service in a medically underserved setting. Int J Psychiatry Med. 2018:53:415-26. https://doi.org/10.1177/ 0091217418791456

52. Horner D, Asher K. General practitioners and mental health staff sharing patient care: working model. Australas Psychiatry. 2005;13:176-80. https://doi.org/10.1080/j.1440-1665.2005.02184.x.

53. Leentjens AFG, van Baalen A, Kuijpers HJH, Lambooij SLE, Schubart $C D$, Sno HN, de Vries ALC, Moret-Hartman M. The revised guideline on consultation-liaison psychiatry of the Netherlands Psychiatric Association. J Psychosom Res. 2018;110:12-4. https://doi.org/10.1016/j.jpsyc hores.2018.04.003.

54. Lee SJ, Crowther E, Keating C, Kulkarni J. What is needed to deliver collaborative care to address comorbidity more effectively for adults with a severe mental illness? Aust N Z J Psychiatry. 2013;47:333-46. https:// doi.org/10.1177/0004867412463975.

55. Morgan D, Kosteniuk J, O'Connell ME, Kirk A, Stewart NJ, Seitz D, Bayly M, Froehlich Chow A, Elliot V, Daku J, et al. Barriers and facilitators to development and implementation of a rural primary health care intervention for dementia: a process evaluation. BMC Health Serv Res. 2019;19:709. https://doi.org/10.1186/s12913-019-4548-5.

56. Ivbijaro GO, Enum Y, Khan AA, Lam SS, Gabzdyl A. Collaborative care: models for treatment of patients with complex medical-psychiatric conditions. Curr Psychiatry Rep. 2014;16:506. https://doi.org/10.1007/ s11920-014-0506-4.

57. Kodish I, Richardson L, Schlesinger A. Collaborative and integrated care for adolescent depression. Child Adolesc Psychiatr Clin N Am. 2019;28:315-25. https://doi.org/10.1016/j.chc.2019.02.003.

58. Norfleet KR, Ratzliff AD, Chan YF, Raney LE, Unutzer J. The role of the integrated care psychiatrist in community settings: a survey of psychiatrists' perspectives. PsychiatrServ. 2016;67:346-9. https://doi.org/10. 1176/appi.ps.201400592.

59. Overbeck G, Davidsen AS, Kousgaard MB. Enablers and barriers to implementing collaborative care for anxiety and depression: a systematic qualitative review. Implement Sci. 2016;11:165. https://doi.org/10. 1186/s13012-016-0519-y.

60. Raney LE. Integrating primary care and behavioral health: the role of the psychiatrist in the collaborative care model. Am J Psychiatry. 2015;172:721-8. https://doi.org/10.1176/appi.ajp.2015.15010017.

61. Sunderji N, Ion A, Huynh D, Benassi P, Ghavam-Rassoul A, Carvalhal A. Advancing integrated care through psychiatric workforce development: a systematic review of educational interventions to train psychiatrists in integrated care. Can J Psychiatry. 2018;63:513-25. https://doi. org/10.1177/0706743718772520.

62. Miller CJ, Sullivan JL, Kim B, Elwy AR, Drummond KL, Connolly S, Riendeau RP, Bauer MS. Assessing collaborative care in mental health teams: qualitative analysis to guide future implementation. Adm Policy Ment Health. 2019;46:154-66. https://doi.org/10.1007/s10488-018-0901-y.

63. Moller MCR, Mygind A, Bro F. Who needs collaborative care treatment? A qualitative study exploring attitudes towards and experiences with mental healthcare among general practitioners and care managers. BMC Fam Pract. 2018;19:78. https://doi.org/10.1186/s12875-018-0764-z.

64. Rousseau C, Nadeau L, Pontbriand A, Johnson-Lafleur J, Measham T, Broadhurst, J. [Youth mental health at the cross roads of service organization]. Sante Ment Que. 2014;39:101-18.

65. Ministère de la Santé et des Services sociaux. Plan d'action en santé mentale 2005-2010 - La force des liens. Québec: Ministère de la Santé et des Services sociaux; 2005.
66. Régie de l'assurance maladie du Québec. Entente concernant l'instauration de modalités de rémunération particulières aux médecins spécialistes répondants en psychiatrie. Annexe 42 à l'Accord-cadre. 2009:91-93. https://www.ramq.gouv.qc.ca/SiteCollectionDocume nts/professionnels/manuels/154-brochure-1-specialistes/maj77_acc_ cadre_spec.pdf.

67. Fleury MJ, Grenier G, Vallee C, Aube D, Farand L, Bamvita JM, Cyr G. Implementation of the Quebec mental health reform (2005-2015). BMC Health Serv Res. 2016;16:586.

68. Fleury M-J, Grenier G, Bamvita J-M, Vallée C, Farand L, Chiocchio F. Évaluation du Plan d'actionen santé mentale (2005-2015). Sante Ment Que. 2018:43:15-38.

69. Vérificateur général du Québec: Rapport du Vérificateur général du Québec à l'Assemblée nationale pour l'année 2015-2016. Vérification de l'optimisation des ressources, Automne 2015. Québec: Vérificateur général du Québec; 2015.

70. Tourigny A, Aubin M, Haggerty J, Bonin L, Morin D, Reinharz D, Leduc Y, St-Pierre M, Houle N, Giguere A, et al. Patients' perceptions of the quality of care after primary care reform: family medicine groups in Quebec. Can Fam Physician. 2010;56:e273-282.

71. D'Amours O. Survol historique de la protection de l'enfance au Québec, de 1608 à 1977. Serv Soc. 1986;35:386-415.

72. Institut national d'excellence en santé et en services sociaux (INESSS): Guide et normes: L'application des mesures en protection de la jeunesse- Cadre de référence. Québec: INESS; 2019.

73. Sunderji N, Waddell A, Gupta M, Soklaridis S, Steinberg R. An expert consensus on core competencies in integrated care for psychiatrists. Gen Hosp Psychiatry. 2016;41:45-52. https://doi.org/10.1016/j.genho sppsych.2016.05.003.

74. Agyapong VI, Conway C, Guerandel A. Shared care between specialized psychiatric services and primary care: the experiences and expectations of consultant psychiatrists in Ireland. Int J Psychiatry Med. 2011;42:295313. https://doi.org/10.2190/PM.42.3.e.

75. Martin D, Miller AP, Quesnel-Vallee A, Caron NR, Vissandjee B, Marchildon GP. Canada's universal health-care system: achieving its potential. Lancet. 2018;391:1718-35. https://doi.org/10.1016/S0140-6736(18) 30181-8.

76. Moroz N, Moroz I, D'Angelo MS. Mental health services in Canada: barriers and cost-effective solutions to increase access. Healthc Manage Forum. 2020;33:282-7. https://doi.org/10.1177/0840470420933911.

77. Loranger C, Fleury MJ. Factors associated with perceived continuity of care among patients suffering from mental disorders. Community Ment Health J. 2020;56:670-9. https://doi.org/10.1007/s10597-019-00528-z.

78. Senn N, Cohidon C, Breton M, Levesque JF, Zuchuat JC. Patterns of patient experience with primary care access in Australia, Canada, New Zealand and Switzerland: a comparative study. Int J Qual Health Care. 2019;31:G126-32. https://doi.org/10.1093/intahc/mzz092.

79. Institut de la statistique du Québec: Le bilan démographique du Québec. Édition 2019. Québec: Gouvernement du Quéec, Institut de la statistique du Québec; 2019.

80. Fleury M-J. La réforme des soins primaires en Sante Ment Que et le rôle et les stratégies de coordination des omnipraticiens. Sante Ment Que. 2014:39:25-45

81. Pineault R, Provost S, Hamel M, Couture A, Levesque JF. The influence of primary health care organizational models on patients' experience of care in different chronic disease situations. Chronic Dis Inj Can. 2011;31:109-20.

82. Esmail N. Waiting you turn: hospital wating lists in Canada. Vancouver: Fraser Institute; 2009

83. Fleury MJ, Grenier G, Bamvita JM. Relationships among structures, team processes, and outcomes for service users in Quebec mental health service networks. Int J Integr Care. 2020;20:12. https://doi.org/10.5334/ ijic. 4718.

84. Ministère de la Santé et des Services sociaux. Projet de loi no 10 (2015, chapitre 1). Loi modifiant l'organisation et la gouvernance du réseau de la santé et des services sociaux notamment par l'abolition des agences régionales. Québec: Government of Quebec; 2015.

85. Association des médecins psychiatres du Québec (AMPQ). Québec: Association des médecins psychiatres du Québec. 2020. https://ampq. org/la-psychiatrie/quest-ce-quun-medecin-psychiatre/. 
86. Ministère de la Santé et des Services Sociaux. Plan d'effectifs médicaux (PEM) en spécilaité en date du 2021-02-26. Québec: Ministère de la Santé et des services sociaux; 2021.

87. Pluye $\mathrm{P}$, Hong QN. Combining the power of stories and the power of numbers: mixed methods research and mixed studies reviews. Annu Rev Public Health. 2014;35:29-45. https://doi.org/10.1146/annurevpublhealth-032013-182440.

88. Carter N, Bryant-Lukosius D, DiCenso A, Blythe J, Neville AJ. The use of triangulation in qualitative research. Oncol Nurs Forum. 2014;41:545-7. https://doi.org/10.1188/14.ONF.545-547.

89. Titscher S, Wodak R, Meyer M, Vetter E. Methods of text and discourse analysis. London: Sage Publications; 2000.

90. Commissaire à la santé et au bien-être (CSBE). Rapport d'appréciation de la performance du système de santé et et de services sociaux. Pour plus d'équité et de résultats en Sante Ment Que. Québec: Commissaire à la santé et au bien-être; 2012.

91. Fleury MJ, Imboua A, Aube D, Farand L. Collaboration between general practitioners (GPs) and mental healthcare professionals within the context of reforms in Quebec. Ment Health Fam Med. 2012;9:77-90.

92. Farrer LM, Walker J, Harrison C, Banfield M. Primary care access for mental illness in Australia: patterns of access to general practice from 2006 to 2016. PLoS One. 2018;13:e0198400. https://doi.org/10.1371/journal. pone.0198400.

93. Fleury MJ, Grenier G, Vallee C, Aube D, Farand L. Implementation of integrated service networks under the Quebec mental health reform: facilitators and barriers associated with different territorial profiles. Int J Integr Care. 2017:17:3. https://doi.org/10.5334/ijic.2482.

94. Milam-Miller S. The psychiatrist as consultant: working within schools, the courts, and primary care to promote children's mental health. Psychiatr Clin North Am. 2009;32:165-76. https://doi.org/10.1016/j.psc. 2008.10.002.

95. Fleury M-J, Grenier G, Bamvita JM, Perreault M, Caron J. Typology of adults diagnosed with mental disorders based on socio-demographics and clinical and service use characteristics. BMC Psychiatry. 2011;11:67.

96. Philibert MD, Pampalon R, Hamel D, Thouez J-P, Loiselle CG. Material and social deprivation and health and social services utilisation in Québec: a local-scale evaluation system. Soc Sci Med. 2007;64:1651-64.

97. Statistics Canada. Access to a regular medical doctor, 2014. 2015. https://www.statcan.gc.ca/pub/82-625-x/2015001/article/14177-eng.
98. Laugharne R, Flynn A. Personality disorders in consultation-liaison psychiatry. Curr Opin Psychiatry. 2013;26:84-9. https://doi.org/10.1097/ YCO.0b013e328359977f

99. van Boekel LC, Brouwers EP, van Weeghel J, Garretsen HF. Healthcare professionals' regard towards working with patients with substance use disorders: comparison of primary care, general psychiatry and specialist addiction services. Drug Alcohol Depend. 2014;134:92-8.

100. Shaw RJ, Wamboldt M, Bursch B, Stuber M. Practice patterns in pediatric consultation-liaison psychiatry: a national survey. Psychosomatics. 2006:47:43-9. https://doi.org/10.1176/appi.psy.47.1.43.

101. O'Neill S, Rajendran K, Mahbubani SM, Halperin JM. Preschool predictors of ADHD symptoms and impairment during childhood and adolescence. Curr Psychiatry Rep. 2017;19:95. https://doi.org/10.1007/ s11920-017-0853-Z

102. Portzky G, Audenaert K, van Heeringen K. Adjustment disorder and the course of the suicidal process in adolescents. J Affect Disord. 2005;87:265-70. https://doi.org/10.1016/j.jad.2005.04.009.

103. Gorman DA, Gardner DM, Murphy AL, Feldman M, Belanger SA, Steele MM, Boylan K, Cochrane-Brink K, Goldade R, Soper PR, et al. Canadian guidelines on pharmacotherapy for disruptive and aggressive behaviour in children and adolescents with attention-deficit hyperactivity disorder, oppositional defiant disorder, or conduct disorder. Can J Psychiatry. 2015;60:62-76. https://doi.org/10.1177/070674371506000 204.

104. Goodrich DE, Kilbourne AM, Nord KM, Bauer MS. Mental health collaborative care and its role in primary care settings. Curr Psychiatry Rep. 2013;15:383. https://doi.org/10.1007/s11920-013-0383-2.

105. Provan KG. Services integration for vulnerable population: Lessons from community mental health. Fam Community Health. 1997;19:19-30.

106. Dill A, Rochefort DA. Coordination, continuity, and centralized control: a policy perspective on service strategies for the chronic mentally ill. J Soc Issues. 1989;45:145-59.

\section{Publisher's Note}

Springer Nature remains neutral with regard to jurisdictional claims in published maps and institutional affiliations.
Ready to submit your research? Choose BMC and benefit from:

- fast, convenient online submission

- thorough peer review by experienced researchers in your field

- rapid publication on acceptance

- support for research data, including large and complex data types

- gold Open Access which fosters wider collaboration and increased citations

- maximum visibility for your research: over $100 \mathrm{M}$ website views per year

At BMC, research is always in progress.

Learn more biomedcentral.com/submissions 